\title{
Person-Situation Dynamics in Educational Contexts: \\ A Self- and Other-Rated Experience Sampling Study of \\ Teachers' States, Traits, and Situations
}

Loes Abrahams ${ }^{1}$, John F. Rauthmann ${ }^{2}$, \& Filip De Fruyt ${ }^{1,3}$

\author{
${ }^{1}$ Ghent University, Belgium \\ ${ }^{2}$ Bielefeld University, Germany \\ ${ }^{3}$ Institute Ayrton Senna Chair at Ghent University
}

This paper has been accepted for publication at European Journal of Personality (February $15,2021)$. This version has not been copy-edited.

Please cite this version as:

Abrahams, L., Rauthmann, J. F., \& De Fruyt, F. (accepted). Person-Situation Dynamics in Educational Contexts: A Self- and Other-Rated Experience Sampling Study of Teachers' States, Traits, and Situations. European Journal of Personality.

\footnotetext{
Author Notes

All materials, data, analyses, and Supplementary Materials are openly accessible at https://osf.io/p642h/.
}

This research was supported by a BOF-grant (BOF.DOC.2017.0044.01) awarded to Loes Abrahams. Loes Abrahams also benefited from a grant from the Institute Ayrton Senna Chair at Ghent University at the beginning of this research.

We thank Niclas Kuper who made us aware of data merging issues in our code. We were thus able to correct critical issues before the paper went to production.

Address correspondence to: Loes Abrahams, Department of Developmental, Personality and Social Psychology, Henri Dunantlaan 2, B-9000 Gent, Belgium. Loes.Abrahams@UGent.be. Tel: +3292646429. 


\begin{abstract}
The situations people find themselves in and how they experience them is fundamental to a host of life and work outcomes. However, most research has so far only relied on self-reports and is thus not able to disentangle different situation components. The present study therefore examined the dynamics between self- and other-rated situation characteristics, personality traits, and personality states in an educational setting. One hundred and seventy-three student teachers ( $n=2,244-2,261$ observations) and 94 supervisors ( $n=1,110-1,122$ observations) participated in a 13- or 14-day experience sampling study during student teachers' internships and rated situations and teachers' personality states twice daily. Answering three research questions yielded that 1) self-rated traits were mostly not associated with self- or supervisorrated situation characteristics; 2) self- and supervisor-rated situation characteristics predicted self- and supervisor-rated personality state expressions (although effects were largest for same-rater associations); and 3) there were no interaction effects of traits and situation characteristics on personality state expressions. These results have important theoretical and applied implications as they advance our understanding of person-situation dynamics in an applied setting and suggest that associations between situations and personality states are not solely attributable to common rater effects.
\end{abstract}

Keywords: situations, personality, person-situation dynamics, observer ratings, education 
Undoubtedly, both person and situation variables shape human experience and behavior. The winding down of the person-situation debate and the now generally accepted recognition that persons and situations work together to produce behavior has led to a tremendous surge in research on psychological situation characteristics over the past few years (Horstmann \& Ziegler, 2019). Using newly developed taxonomies of situation characteristics such as the DIAMONDS (Rauthmann et al., 2014) and CAPTION (Parrigon et al., 2017) dimensions, recent studies have significantly advanced our understanding of the dynamics between personality, situations, and behavior (Breil et al., 2019; Hong et al., 2020; Rauthmann et al., 2020b; Rauthmann et al., 2015c; Serfass \& Sherman, 2013; Sherman et al., 2010; Sherman et al., 2015; Wood et al., 2019).

However, due to mainly relying on self-reported perceptions of situations by raters in situ, a major and recurring challenge for research on person-situation dynamics has been to separate individuals' unique perception or construal of a situation from more objective or consensual evaluations (Rauthmann et al., 2015c; Sherman et al., 2015). Nevertheless, understanding how each of these distinct situation components varies as a function of an individual's personality may significantly advance our insight into why people respond to situations the way they do.

In response to this, using a sample of student teachers and their internship supervisors, the present study includes self- and informant-reports of personality states and situations to examine the within-person associations between teachers' personality traits, states, and situation characteristics during a teaching practicum. Importantly, the inclusion of an informant enables not only the access to observer ratings of personality states, but additionally allows for the disentanglement of various situation components, such as teachers' own perception of the situation, their supervisor's perception of the situation, the 
consensus between their situation perceptions, and each individual's unique situation perception.

The main contributions of this research are therefore twofold and intertwined. First, by including an external rater of psychological situation characteristics and personality states, the present study contributes to basic research on person-situation dynamics and overcomes previous challenges that are related to the sole reliance on self-reports. Second, our work is relevant as an illustration of person-situation dynamics in an applied (education) setting. Next to providing an ideal research context to include observers and thereby contributing to theory development on person-situation dynamics, the current study also serves to demonstrate how such dynamics may be expressed in a practical context. Understanding the dynamics of person-situation transactions at work or in the classroom may, for example, contribute to a better insight into the antecedents of various occupational outcomes. The paper is structured around these two contributions, in which we first discuss research on person-situation dynamics and its potential challenges from a personality psychology perspective, and subsequently discuss how applied (education) research can both provide a solution and benefit from this as well.

\section{Background}

\section{Situation Research and Person-Situation Dynamics}

\section{Situation Characteristics and Taxonomies}

Already for almost a century, psychologists have postulated that human behavior is a function of both the person and the situation (Funder, 2016; Horstmann \& Ziegler, 2016; Lewin, 1936, 1951). However, while psychologically important characteristics of persons have been studied exhaustively by personality psychologists, a similar characterization of situations has been remarkably absent until recently (Rauthmann et al., 2014). Psychological situation characteristics, capturing the psychologically important meanings of situations (e.g., 
that works needs to be done, that a topic is intellectually stimulating, that somebody might be threatened, etc.), are continuous dimensions that can be used to describe and compare situations (de Raad, 2004; Edwards \& Templeton, 2005).

A recent surge in interest in the description of everyday situations resulted in various independent efforts that have led to (at least) two main comprehensive, psychologically relevant taxonomies of situation characteristics that subsume the gamut of important characteristics (for reviews and integrations, see Horstmann et al., 2018; Rauthmann et al., 2020a; Rauthmann \& Sherman, 2018, 2020). The empirically based DIAMONDS dimensions describe situations based on their level of Duty, Intellect, Adversity, Mating, pOsitivity, Negativity, Deception, and Sociality (Rauthmann et al., 2014), while the lexically based CAPTION dimensions describe situations based on their level of Complexity, Adversity, Positive Valence, Typicality, Importance, humOr, and Negative Valence.

Rauthmann and Sherman (2018) examined the empirical and theoretical convergences between the CAPTION and DIAMONDS dimensions and concluded that five replicable common dimensions could be retrieved (i.e., Negative Valence/Adversity, Adversity/Negativity, Importance/Duty, Complexity/Intellect, and Positive Valence/pOsitivity). More recently, Rauthmann and Sherman (2020) reviewed the overlap between the DIAMONDS and CAPTION dimensions and five other taxonomies of psychological situation characteristics that have been developed in the last decade. This suggested the existence of not five but six main situation dimensions: the five dimensions found in their previous work and an additional factor involving the mundaneness of the situation. The current research will make use of dimensions from both the DIAMONDS and CAPTION taxonomies, and includes items for each of these "Replicable Six" dimensions (Rauthmann \& Sherman, 2020, p. 474).

\section{Unraveling Different Situation Components}


Although the development of these situation taxonomies has constituted an impressive leap forward for personality and social psychology research, this has also introduced new questions and methodological challenges. A prevailing issue that occupies situation researchers concerns the question whether situations should be operationalized in more objective or subjective terms (Murray, 1938; Rauthmann \& Sherman, 2019, for a nuanced discussion). Objective conceptualizations stress the "actual situation" or how it "really" is. When focusing on situation characteristics, this requires adopting a consensus position: The way a situation is normatively seen by several people of a given socio-culture constitutes a form of social reality. Rauthmann et al. (2015c) have used the term "situation contact" to refer to this situation component. In contrast, subjective conceptualizations stress the "perceived situation" or how it seems to individuals. There are two ways this perspective is instantiated: one individual's perception of a situation is simply a "situation experience" - the way she or he sees her or his situation. This experience, however, actually confounds situation contact and another important component: "situation construal" (Rauthmann et al., 2015c). The latter captures personal reality, that is, an individual's unique and idiosyncratic perception of a situation independent of (or controlled for) the normative perceptions. The importance of individuals' subjective appraisal of situations is widely recognized and undisputed (Hogan, 2009), and various researchers even argue that individuals' behavior is more strongly affected by the person's perception of the situation than by the "objective" situation itself (Furr \& Funder, 2018). However, it is important to consider contact, experience, and construal jointly (Rauthmann et al., 2015c), as we will do in this work. While previous research has emphasized the distinction between these different situation components (Funder, 2016; Morse et al., 2015a; Rauthmann et al., 2015c; Sherman et al., 2013), there is no agreement yet upon the best method to compute them. Various studies have used inventive methods in which ratings of individuals experiencing a certain 
situation (i.e., raters $i n$ situ) were augmented by ratings of raters ex situ (who rated situations based on factual descriptions of the situation). However, situation vignettes provided are already pre-filtered and possibly biased by the raters in situ given that raters in situ decide which situations and which cues of those situations they report (Hong et al., 2020;

Rauthmann, 2015; Rauthmann et al., 2015c; Sherman et al., 2013). Alternatively, researchers have argued that the ultimate research design would be one in which not only raters in situ but also raters juxta situm, who observe the situation from an outsider's perspective but do not actively take part in it, rate the situation as it naturally evolves (Hong et al., 2020; Rauthmann et al., 2015b). However, obtaining informant reports in ambulatory assessment is highly challenging (e.g., Finnigan \& Vazire, 2018), and it has been rightfully argued that the inclusion of raters juxta situm raises issues on practical, technological, ethical, and perhaps even legal levels (Rauthmann et al., 2015c, p. 109).

Nonetheless, there are contexts for which juxta situm ratings can be obtained. Certain training contexts, such as the teaching internship in the current study, involve intensive levels of supervision which enables the inclusion of a rater juxta situm without having to impose one. Such exceptional settings allow sampling situation data from raters in situ (i.e., student teachers in this case) and juxta situm (i.e., internship supervisors), while also being able to differentiate the situation components mentioned earlier (contact, experience, construal). A design harnessing such data may contribute to a more in-depth understanding of how situations - and distinct perceptions of those situations - are experienced on a daily basis. Even when the situation is more constrained, i.e., all student teachers are enrolled in a teaching internship, participants may experience different situations from day to day.

\section{Traits, States, and Situations}

Several recent studies have empirically demonstrated that individuals' personality traits and states (e.g., HEXACO, Big Five) are meaningfully associated with the kinds of 
situations people find themselves in (i.e., contact), how they perceive their situations (i.e., experience), and the unique way they construe them (e.g., Horstmann et al., 2020; Jones et al., 2017; Morse et al., 2015a; Rauthmann et al., 2015c; Serfass \& Sherman, 2013; Sherman et al., 2013). This may not be surprising, as the five common dimensions of the DIAMONDS and CAPTION taxonomies seem to correspond quite well with the Big Five personality traits (e.g., Duty/Importance - Conscientiousness; Rauthmann \& Sherman, 2020). However, various studies have demonstrated that associations between situation and personality characteristics are not limited to those alone (e.g., Jones et al., 2017; Rauthmann et al., 2015c). A summary of these relations, which are also predicted in the current study, is provided in Table 1.

\section{--- TABLE 1 HERE ---}

The current research contributes to further identifying the dynamic associations between traits, states, and situations in an applied context such as the school setting. This responds also to recent calls from the area of work and organizational psychology for more research on the role of situational features at the workplace and "adopting comprehensive, taxonomy-based perspectives" (e.g., Dalal et al., 2020, p. 436).

\section{Person-Situation Dynamics in an Education Setting}

Examining person-situation dynamics in an education setting, as done in the present study, serves at least two important goals on both a theoretical and applied level. First and foremost, (work) settings with a high level of supervision, such as the teaching internship, naturally allow for the inclusion of an informant that also rates the target's situations and personality states. This way, this particular setting allows for a fundamental methodological improvement in research on person-situation dynamics. Second, extending research on person-situation dynamics — which is typically carried out with student samples (e.g., Horstmann et al., 2020; Rauthmann et al., 2015c; Sherman et al., 2015)—-to an applied 
context may also significantly advance our knowledge on how such dynamics between persons and situations present themselves in an education setting.

Such findings may be especially relevant for researchers on an applied level. Personsituation dynamics may, for example, help explain a variety of work-related outcomes. Specifically attending to teachers' situation experiences, this could, for example, mean that teachers who perceive situations as more adverse may be more prone to suffer from burnout or to be less satisfied with their jobs. However, if teachers perceive situations as adverse but they are in fact not adverse (according to others), this could be relevant to know with regard to how to coach and support teachers in order to feel better at work and be more productive. Research on dynamic person-situation transactions and their consequences is slowly making its entrance into applied psychology (e.g., Green et al., 2018; Huang \& Ryan, 2011; Judge \& Zapata, 2015; Wood et al., 2019). Although researchers have started to recognize the problems associated with "searching for the effect of personality traits while disregarding or minimizing the influence of the contexts that these traits operate within" (Huang \& Ryan, 2011, p. 451), empirical findings in applied contexts remain sparse.

Moreover, while the importance of within-person processes has been underscored and many personality theories focus at the within-person level (Dalal et al., 2020), the majority of study designs are still between-person in nature (especially in educational psychology; Murayama et al., 2017). However, this provides little information on the processes and mechanisms responsible at the intra-individual level (McCormick et al., 2020; Molenaar, 2004). Relatedly, there have mostly been efforts to understand how either (stable) individual differences or environmental characteristics independently affect educational outcomes (e.g., Kim et al., 2019; Klusmann et al., 2008b; Tsai et al., 2008), while not much is known about how one may relate to the other, both between and within individuals. Nevertheless, as Klassen and Kim (2017, p. 8) also argue, teachers' personal characteristics such as traits and 
states interact with contextual factors to shape pre-service and in-service teacher professional outcomes. Additionally, although some studies in education seem to acknowledge the appraisal component that shapes the interpretation of the environment (e.g., perceived school context and teacher burnout and job satisfaction; Skaalvik \& Skaalvik, 2009), only a few studies have investigated how individual differences may affect such subjective appraisals (e.g., Cho \& Shim, 2013).

\section{The Current Work}

The present study aims to contribute to research on person-situation dynamics by examining such dynamics in an applied setting (i.e., education), and includes a set of research questions related to the contact, experience, and construal of characteristics (within the DIAMONDS/CAPTION models) of (teaching-related) situations. A crucial feature of our study's design including both student teachers and their internship supervisors is that it provides researchers with an excellent opportunity to study situations with an experienced rater juxta situm, and thus answers to previous calls for the inclusion of situation ratings beyond in situ raters (and personality; e.g., Hong et al., 2020; Huang \& Ryan, 2011; Noftle \& Gust, 2019; Rauthmann et al., 2016; Rauthmann et al., 2015c; Sherman et al., 2015).

Including both self- and other-ratings, the current work examines not only student teachers' own perception of the situation but rather focuses on a comprehensive set of situation components. Specifically, for situation perceptions, we were able to tease apart five different situation components in the data from student teachers (in situ) and supervisors (juxta situm), as shown in Figure $1^{1}: 1$ ) teacher-rated situation experience (i.e., raw in situ

\footnotetext{
${ }^{1}$ Note that our situation components are slightly different from those in Rauthmann et al. (2015). Given that we have one observer present in the situation (instead of two to four raters of a written situation vignette as in Rauthmann et al., 2015), our situation components refer to distinctions between teachers' and supervisors' ratings of situations rather than to the distinction between an individual's own rating and a consensual perspective by multiple raters. Figure 1 shows these relations. Given this difference with previous studies, we chose to use the term teacher- or supervisor-centered situation construal instead of teacher's or supervisor's idiosyncratic situation perception, as technically they are not identical constructs (although they are very similar).
} 
ratings), 2) supervisor-rated situation experience (i.e., raw juxta situm ratings), 3) consensusfocused situation contact (i.e., shared variance between in situ and ex situ ratings), 4) teacherfocused situation construal (i.e., idiosyncratic in situ ratings controlled for juxta situm ratings), and 5) supervisor-focused situation construal (i.e., idiosyncratic juxta situm ratings controlled for in situ ratings).

\section{--- FIGURE 1 HERE ---}

As ratings of only one rater juxta situm could be included, we aim to stress that in the present study, situation construal and situation contact reflect one individual's in situ rating controlled for the other individual's juxta situm rating (or the other way around; i.e., situation construal), or the overlap between the two (i.e., situation contact). In this sense, the current study's focus is not on objective features of the situation, but rather on how two individuals' agreement - one in situ and one juxta situm — regarding psychological situation characteristics relates to personality traits and states.

Situation dimensions included in this study represent a combination of a subset of the DIAMONDS (Rauthmann et al., 2014) and CAPTION (Parrigon et al., 2017) dimensions (see Measures). Based on previous findings (e.g., Rauthmann et al., 2016; Rauthmann et al., 2015c), various associations between personality states/traits and situation characteristics were predicted (see Table 1). Notably, the expected effects in Table 1 are only content-driven (for which pairs of personality domains and situation characteristics do we expect sizable and statistically significant associations?), but we did not a priori derive expectations for which of the five situation components (see Figure 1) we would find which kinds of effects. Specifically, three increasingly comprehensive research questions were formulated (see Figure 2), focusing on primary questions regarding the relationships among traits, states, and situations (Nezlek, 2007). In each of these questions we examined all five situation components as outlined above. This study, its research questions, and hypotheses were not 
pre-registered. All materials (original items in Dutch with their closest English translations), data, analyses, and Supplementary Materials of this study are openly accessible at https://osf.io/p642h/.

\section{--- FIGURE 2 HERE ---}

\section{Question 1: How Are Student Teachers' Personality Traits Associated with the Situations They Find Themselves in?}

Our first research question (RQ) examined to what extent student teachers' selfreported personality traits are related to self- and supervisor-rated situations in class. In doing so, the current research aims to replicate previous findings on the relationship between personality traits and situation experiences in a different setting (e.g., Sherman et al., 2015; Wilt \& Revelle, 2019; Wrzus et al., 2016; Ziegler et al., 2019). Importantly, recent studies suggested that personality traits may be differentially associated with situation experience, contact, and construal (Hong et al., 2020; Morse et al., 2015a; Morse et al., 2015b; Rauthmann et al., 2015c; Serfass \& Sherman, 2013; Sherman et al., 2013), underscoring the current study's focus on all five situation components. For example, do more extraverted teachers experience more positive situations? Or, do they rather perceive (i.e., construe) situations as being more positive?

\section{Question 2: How Are the Situations Student Teachers Find Themselves in Associated with Their Momentary Personality State Expressions?}

Situations may further be associated with momentary state expressions of personality (Breil et al., 2019; Huang \& Ryan, 2011; Noftle \& Gust, 2019; Wilson et al., 2017; Wood et al., 2019). For example, when one experiences or construes a situation as being intellectual, this may stimulate the individual's momentary state Openness (Rauthmann et al., 2016; Sherman et al., 2015). Using cross-lagged models in which either situation experiences predicted later personality states, or in which personality states predicted later situation 
experiences, Rauthmann et al. (2016) found only slightly more evidence for situation experiences predicting personality states than vice versa. The current study also adopts the view that situations can shape momentary state expressions (see Figure 2), but we cannot rule out a reverse directionality given the cross-sectional nature of the analyses in this study. ${ }^{2}$

\section{Question 3: How Do Student Teachers' Personality Traits Play a Role in the Association}

\section{Between Their Situations and Momentary Personality State Expressions?}

Following previous research (e.g., Breil et al., 2019; Sherman et al., 2015; Wood et al., 2019) and based upon the assumption that persons (i.e., personality traits) and situations jointly shape individuals' behavior (i.e., personality states), we also examined how situations (self- and supervisor-rated), self-reported personality traits, and their interactive effects are associated with momentary expressions of personality states (self- and supervisor-rated). Such an interaction between personality traits and situation characteristics reflects the extent to which, for example, trait levels of Conscientiousness are associated with more conscientious behavior (i.e., state Conscientiousness) in situations that are high in Duty. Previous studies have produced mixed findings. For example, some research focusing mainly on situation experiences suggested that personality traits do moderate situation-behavior interactions (e.g., Breil et al., 2019; Wood et al., 2019), whereas others found more limited evidence for this (e.g., Sherman et al., 2015) . We extend previous research by focusing on a complete set of situation components and on a broad set of situation characteristics.

\section{Method}

\section{Participants}

All participating teachers were second-year student teachers of a Bachelor's degree in Primary Education at a University of Applied Sciences in Flanders, Belgium. Student

\footnotetext{
${ }^{2}$ We note that, in principle, cross-lagged analyses could also be conducted on our data set. However, the present study's focus was on momentary associations between personality states and situations instead, leading to the use of cross-sectional analyses. Furthermore, lags between observations may have been too long and differently dispersed across individuals, making true cross-lagged analyses difficult to implement and interpret.
} 
teachers kindly participated in our study during their internship in a $5^{\text {th }}$ or $6^{\text {th }}$ grade class of a public elementary school, where they were (each individually) supervised by an internship supervisor. We combined data from two samples that were collected in two consecutive cohorts of student teachers.

Data from Sample 1 were gathered in March and May 2018 and comprised 78 student teachers and 49 internship supervisors. Each supervisor supervised only one student teacher, but not all supervisors wished to participate in our study, resulting in a lower number of supervisors than student teachers in our samples. Data from Sample 2 were gathered during March-May 2019 and comprised 116 second-year student teachers and 62 supervisors. This leads to an initial total sample of 194 student teachers and 111 supervisors. In other words, 111 of these 194 student teachers had supervisor ratings. Our final sample, after data cleaning (for more details see below), consisted of 173 student teachers $(18-32$ years old; $M=20.03$, $S D=1.83 ; 154$ female $)$ and 98 supervisors $(22-59$ years old; $M=37.28, S D=10.54$; three did not state their age; 73 female).

Student teachers and supervisors of Sample 1 received $€ 20$ for participation in the study regardless of their compliance rates. In Sample 2, only student teachers received a cinema ticket (worth approximately $€ 10$ ) for completing the study. Level 2 sample size was largely determined based on the availability of participants within one teacher education program, taking into account the practical restrictions the present study design poses (e.g., the total number of student teachers enrolled and their supervisors' willingness to participate). This study was approved by the Ethics Committee of Ghent University.

\section{Procedure}

In both Sample 1 and Sample 2, all second-year student teachers of one particular teacher education program were invited for an on-campus information session on the project. In Sample 1, student teachers interested in participation were requested to give their 
supervisor an information leaflet explaining the study and asking for their participation. In Sample 2 student teachers received an email with both a link to sign up for the study and with an information letter that should be forwarded to the supervisor. This letter set out the goals and procedure of the study and contained a link through which supervisors could sign up for participation or decline. In both samples, student teachers could also participate in the study without the participation of their internship supervisor.

Upon signing up for the study, student teachers and supervisors were requested to complete various demographic questions and to provide their informed consent. Additionally, student teachers completed a Big Five trait measure (see Measures). During student teachers' internships, student teachers and supervisors received two notifications daily between 11.35 and 11.45 AM, and between 2.45 and 2.55 PM to answer the surveys online (https://formr.org; Arslan et al., 2020). After two hours the link expired. Participants that did not possess a smartphone were provided with paper-and-pencil questionnaires. ${ }^{3}$ The internships of Sample 1 lasted 14 days, resulting in a total number of 25 assessments per participant (i.e., twice daily but only once on Wednesdays). In Sample 2, the study included 13 days, or 24 assessments (i.e., twice daily except on Wednesdays). Various other teacher-, supervisor, and student-reported variables included in this data collection were not used in the present study.

Paper-and-pencil assessments that were completed too early or too late were excluded. Participants who completed fewer than three valid reports were removed from all analyses. Furthermore, several participants provided no data at all for reasons as early withdrawal from the internship, deciding not to participate after all because of the heavy teaching workload, and participants losing or not returning their paper-and-pencil questionnaires. These participants were, of course, not included in the final data set.

\footnotetext{
${ }^{3} n=16$ student teachers, $n=23$ supervisors.
} 
These procedures led to a final sample of $N=173$ student teachers, or a total of $n=$ $2,244-2,261$ student teacher reports $(M=13.03$ per student teacher, $S D=5.90$, or a response rate of approximately 53\%). ${ }^{4}$ Ninety-four supervisors completed $1,110-1,122$ reports $(M=11.87$ per supervisor, $S D=4.80$, or a response rate of approximately $50 \%)$. ${ }^{5}$ For approximately $n=790$ observations, ratings of both student teacher and supervisor were available. The response rate in these samples is below what is generally reported in ambulatory assessment studies (e.g., 83\% in 895 healthy participants across multiple studies; Rintala et al., 2019), which may reflect certain hindrances associated with the collection of repeated measures data in organizational contexts (see, e.g., Klumb et al., 2009, for a review on methodological issues in ambulatory assessment in I/O psychology). Reassuringly, a recent study found very little evidence that missing experience sampling reports may be systematically associated with variables of interest in a sample of university students (Sun et al., 2020). However, an open question remains whether these findings can be generalized to other samples_-like ours-as well.

\section{Measures}

\section{Big Five Personality Traits}

Student teachers' Big Five personality traits were assessed using the Dutch version of the Big Five Inventory (BFI; Denissen et al., 2008). This measure includes 44 items that assess individuals' trait levels of Extraversion ( 8 items; McDonalds's $\omega=.89$ ), Openness to Experience (10 items; $\omega=.85$ ), Neuroticism ( 8 items; $\omega=.89$ ), Conscientiousness (9 items; $\omega$ $=.89$ ), and Agreeableness (9 items; $\omega=.82)$. All items used a 5-point Likert-type response

\footnotetext{
${ }^{4}$ Note that these means, standard deviations, and response rates are approximations due to the slight variability in the number of observations (depending on the variable of interest).

${ }^{5}$ Eight of the 98 participating supervisors worked part-time and shared a class with another participating supervisor. This means that - after exclusion of several participants based on the aforementioned criteria-90 student teachers had one supervisor that participated in the study, and four had two supervisors. For the following analyses, data of supervisors who shared a class with another supervisor were combined and were regarded as one full-time supervisor.
} 
scale ranging from 1 ("completely disagree") to 5 ("completely agree"). Means and standard deviations of each of the Big Five personality traits are provided in Table 2.

\section{--- TABLE 2 HERE ---}

\section{Big Five Personality States}

Big Five personality states were assessed using 10 items that each contained two adjectives: Openness: 'imaginative, creative' and 'little resourceful, little original' (R); Conscientiousness: 'diligent, precise' and 'unorganized, negligent' (R); Extraversion: 'spontaneous, exuberant' and 'reserved, distant' (R); Agreeableness: 'friendly, benevolent' and 'rude, condescending' (R); and Neuroticism: 'tense, insecure' and 'in control, confident' (R). These items were based on the Dutch version of the Big Five Inventory (BFI; Denissen et al., 2008), on items used in other experience sampling studies, and on literature on Dutch adjectives that can be used to describe each of the Big Five dimensions (de Raad \& Doddema-Winsemius, 2006). An important criterion was that adjectives should be relevant in (student) teachers' daily practices, and that they were expected to demonstrate considerable variability within persons. Items were assessed on a 5-point Likert-type response scale ranging from 1 ("completely disagree") to 5 (“completely agree") and asked participants to indicate how the teacher behaved during the previous hour.

Means, standard deviations, intraclass correlation coefficients (ICCs), and within- and between-person omega $\left(\omega_{\mathrm{WP}} / \omega_{\mathrm{BP}}\right)$ reliability estimates (Geldhof et al., 2014; McDonald, 1999) of the five dimensions can be found in Table 2. As can be seen in Table 2, all variables exhibit considerable within-person variability, justifying the use of multilevel analysis. Omega reliability coefficients ranged from .23 to .67 at the within-person level, and from .55 to .95 at the between person level. Within-person reliability coefficients may appear rather low by traditional standards, but in ambulatory assessment studies brief scales are used to capture broad domains with few items and to maximize validity in contrast to optimizing 
internal consistency (Wilson et al., 2017, p. 114). Criteria for within-person reliabilities are, therefore, "more relaxed (...) than one might apply for trait measures" (Nezlek, 2017, p. 154). The reliabilities of our Big Five state items are furthermore comparable to what is generally reported in ambulatory assessment studies (e.g., Finnigan \& Vazire, 2018; Sun \& Vazire, 2019; Wilson et al., 2017), although some may be still considered rather low even by those standards. Thus, for certain dimensions we can expect an attenuation of associations found.

\section{Situation Characteristics}

Based on the findings of Rauthmann and Sherman (2018), relevant dimensions of both the DIAMONDS (Rauthmann et al., 2014) and CAPTION (Parrigon et al., 2017) taxonomies were selected and adapted. More specifically, given the theory- and data-driven convergences of five of the DIAMONDS domains with five of the CAPTION domains, only one item for each of these converging domains was included and the DIAMONDS nomenclature retained for them (see Table S1 in the Supplementary Materials for all items). Additionally, of the remaining dimensions (i.e., Mating, Deception, and Sociality from the DIAMONDS and Typicality and Humor from the CAPTION) only those dimensions considered relevant in a teaching context were included. Items were based on short-form measures of the DIAMONDS (S8-I: Rauthmann \& Sherman, 2016) and CAPTION dimensions (CAPTIONs-SF: Parrigon et al., 2017), respectively. In some instances, the content was slightly adapted to tailor items to an educational context. For example, the original Adversity item "Somebody is being threatened, accused, or criticized" was changed to "Somebody was being reprimanded or criticized", because reprimands may be more common in classroom situations than threats and accusations. Items were assessed on a 5point Likert-type response scale ranging from 1 ("completely disagree") to 5 ("completely agree") and asked participants to indicate the extent to which the item applied to the overall 
situation of the previous hour. ${ }^{6}$ Means, standard deviations, and intraclass correlation coefficients are provided in Table 2. Within- and between-person correlations between teacher- and supervisor-rated situation characteristics can be found in Table S2 in the Supplementary Materials.

\section{Data-Analytical Strategy}

The following analyses focus on the five situation components outlined in Figure 1. First, teacher-rated and supervisor-rated situation experience is simply the raw rating in situ by student teachers or juxta situm by their one supervisor, respectively (see left panel of Figure 1). Second, consensus-focused ratings were used here conceptually as a proxy for situation contact and represent the covariance portion shared among ratings in situ and juxta situm (see middle panel of Figure 1). This was computed by running a factor analysis on the situation ratings by the two sources and then saving the individual factor scores, which is an approach that has been employed in similar previous work as well (e.g., Rauthmann et al., 2015c). Finally, teacher-focused and supervisor-focused situation construal represented residualized scores, respectively (see right panel of Figure 1). Specifically, scores from one rating source were regressed on the other, and then the standardized residuals were saved. We next used these scores in different analyses as outlined in the research questions above. In all analyses we included situation perceptions at Level 1. The exact specification of each of these models can be found under Results.

All linear mixed effect models were constructed using the lme4 package (Bates et al., 2015) in R version 4.0.2 (R Core Team, 2020). Further, all models included random intercepts, but random slopes were left out due to possible convergence issues in some of the models. To improve convergence, all models included the optimizer = "bobyqa". In all

\footnotetext{
${ }^{6}$ In this applied study context, we could not expect participants to evaluate the situation (or other variables) at the exact time they received a signal. This is discussed in more detail in Limitations and Prospects.
} 
analyses, personality trait scores were grand mean centered, and situation characteristics and personality states within-person centered. In the following sections, full results of all research questions are provided and report unstandardized fixed effects estimates, confidence intervals, and marginal multiple $R_{\mathrm{s}}\left(R_{m}\right)$, which reflect the model fit for the fixed effects of the models (Nakagawa \& Schielzeth, 2013). ${ }^{7}$ Standardized regression coefficients—which are recommended as effect size measures for multilevel models (Lorah, 2018; Snijders \& Bosker, 2012)—were calculated using the standardize parameters function of the effectsize package (Ben-Shachar et al., 2020). All effect sizes are provided in the Supplementary Materials, and a visualization of their distribution is shown in Figure 3. To account for multiple comparisons, we used the conservative significance level of $p<.001$ for determining the statistical significance of effects. For each research question, various illustrations on how to interpret the results will be provided below, but due to space limitations, not all results can be discussed explicitly.

\section{Results}

\section{Question 1: Associations Between Personality Traits and Situation Characteristics}

In Research Question (RQ) 1, we predicted each component of all situation characteristics from teachers' self-reported traits. Only traits assumed to be associated with that respective situation characteristic were included (see Table 1). For example, we predicted teacher-rated experience of Positivity simultaneously from trait Extraversion, Agreeableness, and Neuroticism.

Prior to computing these linear mixed models, we examined between-person correlations between teachers' self-reported personality traits and self- and supervisor-rated situation characteristics (Table 3). All five personality traits correlated significantly with self-

\footnotetext{
${ }^{7}$ Variance explained by the fixed factors in the models is reflected by $R^{2}$, and can therefore be calculated by taking the square of $R_{m}$ (Nakagawa \& Schielzeth, 2013).
} 
and supervisor-rated situations, except Conscientiousness, which only correlated significantly with teacher-rated situations. The size of the correlations that reached a statistical significance level that was at least below $p<.05$ ranged from $|.15|$ to $|.40|$ (average $|r|=.24$ ).

\section{--- INSERT TABLE 3 HERE ---}

As displayed in Table 4, results of the linear mixed effect models indicated that only one of the 70 predicted associations (i.e., 14 associations x 5 situation components; $1 \%$ ) between teachers' self-reported personality traits and situation characteristics was statistically significant at $p<.001$. Specifically, such a significant association between trait Openness and teacher-focused situation construal of Intellect was found. The unstandardized multilevel regression coefficient of 0.39 reflects that for every 1-point increase in Openness, we would expect to find a 0.39 increase in the average level of Intellect construed by teachers. No statistically significant associations at $p<.001$ between personality traits and teacher-rated situation experience, consensus-focused situation contact, supervisor-rated situation experience, or supervisor-focused situation construal were found (second to fifth panels Table 4).

\section{--- INSERT TABLE 4 HERE ---}

Furthermore, marginal multiple $R \mathrm{~s}\left(R_{m}\right)$ suggested that, overall, the associations between personality traits and situation characteristics were small, as the average $R_{m}$ was .12 and none of the models' $R_{m}$ s exceeded .27 . All standardized regression coefficients and their confidence intervals can be found in Table S3 in the Supplementary Materials. The effect size of the one significant association (at $p<.001$ ) was $\beta=.22$. A visualization of all effect sizes is provided in Figure 3 (left panel).

\section{Question 2: Associations Between Situation Characteristics and Personality States}


In RQ2, we predicted teacher- or supervisor-rated personality states from situation characteristics. Each model only included one type of situation component, but all expected situation characteristic(s) from Table 1 were entered simultaneously. For example, teacherreported state Extraversion was predicted from teacher-rated experience of Adversity, Positivity, Negativity, and Humor, and in a different model from teacher-focused construal of Adversity, Positivity, Negativity, and Humor, and so on.

We first examined correlations before computing linear mixed models. Within-person correlations between teacher- or supervisor-reported personality states and each of the situation characteristics and components are provided in Table 5. All five situation components correlated significantly with self- and supervisor-ratings of teachers' personality states. The size of the correlations that reached a statistical significance level that was at least below $p<.05$ ranged from $|.07|$ to $|.43|$ (average $|r|=.21$ ). Between-person correlations can be found in Table S4 in the Supplementary Materials.

\section{--- INSERT TABLE 5 HERE ---}

Table 6 displays the results of the linear mixed effect models that were constructed as outlined above. We found statistically significant effects at $p<.001$ for 66 of the 140 predicted associations (roughly 47\%; i.e., 14 associations x 5 situation components x 2 raters of personality states). These within-person effects reflect the extent to which momentary changes relative to one's average situation experiences were associated with changes in personality expressions. In the following, we illustrate several findings.

\section{--- INSERT TABLE 6 HERE ---}

First, the results of the models reveal many statistically significant within-person associations between teacher- or supervisor-rated situation experience and personality states. When teachers experienced, for example, more Positivity or Humor in a situation than they usually did, this was associated with higher levels of self-reported state Extraversion, while 
the experience of more Negativity than usual was associated with lower levels of state Extraversion (upper left panel Table 6). For some associations-although only few-, this was also reflected in supervisor-reports of teachers' personality states. For example, when teachers experienced more Humor in a situation, this was also reflected in higher supervisorratings of teachers' state Openness (lower left panel Table 6). The notion that associations between situation experiences and personality states were not only found for the individuals acting in the situation, was reflected in a plethora of statistically significant associations between supervisor-rated situation experience and teacher- and supervisor-rated personality states (fourth panel Table 6). For example, when supervisors experienced a situation as high on Duty, this was reflected in higher ratings of state Conscientiousness according to both supervisors and teachers.

Second, many statistically significant associations were also observed between teacher- or supervisor-focused situation construal and personality states (second and right panels Table 6). For example, when teachers perceived situations as more humorous than the average situation they encountered, this was associated with higher state Openness according to both teachers and supervisors. All other associations were, however, only statistically significant according to one of the raters. Teachers' construal of more Negativity and less Positivity in a situation was, for example, associated with increased self-reported state Neuroticism, but not with supervisor-reported state Neuroticism. Similarly, supervisors' construal of Intellect predicted supervisor-rated state Openness, but not teacher-rated state Openness.

Third, as the middle panel of Table 6 shows, consensus-focused situation contact was widely associated with teachers' self- and supervisor-rated personality states. These findings illustrate, for example, that levels of common source variance of Humor and Intellect in the situation positively predicted both teacher- and supervisor-rated state Openness. Consensus- 
focused situation contact of each situation characteristic, except Adversity and Typicality, predicted the expression of at least one personality state. Furthermore, findings were largely similar for teacher- and supervisor-ratings of personality states.

Although, overall, the proportion of variance explained was rather small, explained variance in same-rater models was considerably larger. That is, $R_{m}$ appeared to be larger in models in which either teacher-rated personality states were predicted by teacher-rated situation experience or teacher-focused construal (upper left and upper second panels Table 6), or in which supervisor-rated personality states were predicted by supervisor-rated situation experience or supervisor-focused construal (lower fourth and lower right panels Table 6). Explained variance in models predicting (teacher- or supervisor-rated) personality states by consensus-focused situation contact also seemed to be larger than the average proportion of variance explained. All standardized regression coefficients and their confidence intervals can be found in Table S5 in the Supplementary Materials. The average effect size of all significant associations at $p<.001$ was $\beta=|.16|(S D=.05)$, and ranged from $|.07|$ to $|.28|$. A visualization of all effect sizes is provided in Figure 3 (middle panel).

\section{Question 3: Moderating Effects of Student Teachers' Personality Traits in the}

\section{Association Between Situations and Momentary Personality State Expressions}

In RQ3, teacher- or supervisor-rated personality states were predicted from 1) their respective personality trait, 2) the relevant situation characteristic(s) (separate analyses for each situation component), and 3) the interaction between the personality trait and situation characteristic(s). An example of a model is teacher-rated state Extraversion that was predicted by 1) teacher-rated trait Extraversion, 2) teacher-rated experience of Adversity, Positivity, Negativity, and Humor, and 3) the four interaction terms between trait Extraversion and the aforementioned situation characteristics. In line with similar previous research (Sherman et al., 2015), our final models only included those interaction effects that 
added unique predictive value (i.e., those that were statistically significant). We expected that selecting interactions that are significant at $p<.001$ would result in no interactions at all; hence, we slightly increased the alpha level here and included interaction terms that were significant at $p<.05$. This more lenient criterion for the inclusion of interaction terms may also support further exploration of the data and generation of hypotheses that can be tested in future research. However, as previously, we only discuss (main and interaction) effects that were significant at the more conservative level of $p<.001$. Prior to estimating the models, we computed within- and between-person correlations between self-rated personality traits and self- and supervisor-rated personality states (Table 7). ${ }^{8}$

\section{--- INSERT TABLE 7 HERE ---}

Table 8 displays the results of each of the linear mixed effect models. The results of the abovementioned example suggest, for example, that teachers higher on trait Extraversion also tended to show higher state Extraversion (teacher-rated only; $b=0.25$ ). Furthermore, when teachers experienced more Positivity or Humor, or less Negativity in the situation than they usually did, this was associated with higher levels of teacher-rated state Extraversion $(b$ $=0.19, b=0.10$, and $b=-0.12$, respectively). Teachers' trait Extraversion did not moderate these associations, as the interactions between trait Extraversion and the experiences of these situation characteristics did not reach our defined level of statistical significance (at $p<.001$ ). While an in-depth discussion of all findings is not feasible, there are several notable patterns in these results.

\section{--- INSERT TABLE 8 HERE ---}

A first pattern is that all personality traits except Openness emerged as statistically significant predictors of their respective state according to teachers' self-ratings. Supervisor-

\footnotetext{
${ }^{8}$ Other relevant correlations can be found in previous tables (i.e., between-person correlations between personality traits and situation characteristics in Table 3, and within- and between-person correlations between personality states and situation characteristics in Table 5 and Table S4, respectively).
} 
rated personality states, however, were not predicted by teachers' self-reported personality traits (at $p<.001)$.

Second and somewhat contrastingly, teacher- and supervisor-rated situation experience, consensus, and construal widely emerged as significant predictors of both teacher- and supervisor-rated personality states. For example, teachers' experience and construal of Humor in the situation predicted both teachers' and supervisors' ratings of teachers' state Openness (first and second panels Table 8), and supervisors' experience of Humor in the situation predicted both teachers' and supervisors' ratings of teachers' state Extraversion and Openness (fourth panel Table 8). Overall, out of 140 predicted associations (i.e., 14 associations $\mathrm{x} 5$ situation components $\mathrm{x} 2$ raters of personality states), 67 were statistically significant (48\%). While this was already suggested in the findings of RQ2, a valuable contribution of RQ3 is that it demonstrates that such effects still hold when controlling for trait levels of personality.

Third, our findings suggest independent effects of personality traits and situation characteristics on state expressions of personality. That is, out of 140 predicted interaction effects (i.e., 14 associations x 5 situation components x 2 raters of personality states), none were statistically significant at $p<.001$ (although seven were significant at $p<.05$ ).

On average, the associations between situation characteristics, personality traits, and personality states were small to moderate (average $R_{m}=.29$ ). However, in several models these associations were considerably larger, for example, in models predicting teacher-rated state Extraversion by teacher-rated situation experience $\left(R_{m}=.41\right)$ and teacher-focused situation construal $\left(R_{m}=.48\right)$. All standardized regression coefficients and their confidence intervals can be found in Table S6 in the Supplementary Materials. The average effect size of all significant associations at $p<.001$ was $\beta=|.19|(S D=.07)$, and ranged from |.07| to |.34|. A visualization of all effect sizes is provided in Figure 3 (right panel). 


\section{Discussion}

The current study examined the dynamics between personality traits, situation characteristics, and personality states in an educational context. While most previous research focused on some of these elements (and there only on specific aspects), the present study demonstrates the importance of each of them for comprehensively understanding behavior. Importantly, the inclusion of supervisor-ratings of situation characteristics and personality states allowed for an inclusive examination of how such dynamics may generalize across rating sources. Findings of our three research questions provided valuable insights.

\section{Interpretation}

\section{Personality Traits and Situation Characteristics}

A first finding that contrasts previous research is that personality traits were mostly unrelated to situation experiences (Rauthmann et al., 2015c; Sherman et al., 2015, Question 3). Although an important advantage of the current study is its broad focus on both self- and other-rated situation perceptions, the only statistically significant association found here was between trait Openness and teacher-focused construal of Intellect. This finding is consistent with relatively heterogeneous conceptualizations of Openness as a trait that reflects a preference for engagement in intellectual activities (DeYoung, 2015), originality, divergent thinking, and creativity (McCrae, 1987), and higher humor abilities (Nusbaum et al., 2017), among others.

Given previous findings (e.g., Rauthmann et al., 2015c; Sherman et al., 2015), it is remarkable, however, that no other associations between personality traits and situation experiences emerged. We cautiously posit that in the current sample of (student) teachers, restriction in variance may have caused some effects to stay under the radar, as our findings indicate that several associations did reach significance at higher alpha levels (i.e., $p<.05$; also see Limitations and Prospects). Our stricter significance criterion may also partly 
explain the discrepancy with previous studies and could suggest that the relationships between personality traits and situation experiences may be less strong than previously thought.

\section{Situation Characteristics and Personality State Expressions}

A second research question demonstrated that situation characteristics are associated with self- and supervisor-ratings of personality states. Although most associations were found when personality states and situation characteristics were rated by the same individual, various statistically significant cross-rater effects were observed as well. Several emerging patterns should be noted.

First, with only two exceptions, we consistently found similar effects for both situation experience and situation construal when looking at same-rater associations. For example, teacher-rated state Extraversion was predicted by both teacher-rated experience and teacher-focused construal of Positivity, Negativity, and Humor, but not by Adversity. While the relative strength of these associations varied, these findings illustrate the importance of including one or more external raters in research on person-situation dynamics so that such different situation appraisals can be separated. We will return to this in Merits and Implications.

Second and importantly, several statistically significant other-rated and cross-rater effects emerged. For example, when teachers uniquely perceived a situation as humorous (i.e., situation construal), this was associated with higher supervisor-rated state Openness. This suggests that within-person variability in situation experiences and personality expressions exists not only in the mind of the actor (Fleeson \& Law, 2015), and that associations between situations and personality states are not (solely) attributable to common rater effects (Podsakoff et al., 2003; see below). 
Third, our results showed that (consensus-focused) situation contact was associated with both teacher- and supervisor-rated personality states, thereby extending previous findings of personality traits and situations (Rauthmann et al., 2015c) to personality states. Our findings demonstrated large levels of (intraindividual) variability in the situations teachers encountered on a daily basis (see, e.g., Table 2), and teachers seemed to modify their in-class personality states accordingly. While a promising finding is that teachers report, for example, higher levels of state Extraversion and Agreeableness in more positive situations, this also means that they report lower levels on these dimensions in situations that are less positive.

\section{Situation Characteristics and Personality States and Traits}

Previous research in educational psychology demonstrated links between teachers' stable individual differences and behaviors in class (e.g., Klusmann et al., 2008a; Schmidt et al., 2017), and between (perceived) characteristics of the school environment and teachingrelated behavior (e.g., Klusmann et al., 2008a; Skaalvik \& Skaalvik, 2009). However, to date it remained unclear how traits may relate to teachers' behaviors in class and their subjective perceptions to in-class situations in a dynamic way. A third research question therefore examined to what extent student teachers' standing on a personality trait may moderate the association between situation characteristics and personality states.

Our results suggested no such interaction effects, which is broadly in line with similar research that found mainly independent associations of personality traits and situation characteristics with personality states (Sherman et al., 2015) but contrasts yet other recent work (e.g., Breil et al., 2019). As mentioned previously, restriction in variance in this specific sample of student teachers may have played a role in the absence of any interactions between personality traits and situation characteristics. Further, interaction effects between personality 
traits and situation experiences may be subtle, and could therefore require (much) larger sample sizes.

A noteworthy additional finding is that (teacher-rated) personality traits predicted teacher-rated but not supervisor-rated personality states. The finding that traits predict states is in line with the predictions of the influential Whole Trait Theory (WTT; Fleeson \& Jayawickreme, 2015) or other empirical findings (e.g., Horstmann \& Rauthmann, in preparation) where density distributions of states are related to traits. The lack of significant associations between personality traits and supervisor-rated personality states may (in part) have been due to common method variance (see, e.g., Podsakoff et al., 2003), as we only obtained teacher-ratings of personality traits (see also Table 7). Therefore, we strongly encourage researchers interested in the dynamics and interactions between personality traits, states, and situation experiences in education or other specific (occupational) groups to replicate and extend the current research with the inclusion of self- and other-ratings of all variables.

\section{Effect Sizes}

In each of our research questions, the average standardized effect sizes that were statistically significant at $p<.001$ ranged between .16 and .22 (see also Figure 3 ). This is broadly in line with or even slightly larger than the effect sizes reported in similar previous research (e.g., Hong et al., 2020; Rauthmann et al., 2015c; Sherman et al., 2013; Sherman et al., 2015). Although these effect sizes may seem small according to traditional standards, it is important to realize that "seemingly small single effects can and do accumulate over time to become important influences on important outcomes" (Rauthmann et al., 2015c, p. 108;

Sherman et al., 2013). In other words, individuals encounter a multitude of situations on a daily basis, so that cumulative effects of single situations may in fact be quite large (Sherman et al., 2013). Using the example of teachers' person-situation dynamics in class, the 
seemingly small relationship between personality traits and distinctive situation perceptions may become quite substantial during a school year or even over the course of one's career.

\section{Merits and Implications}

The findings of this research have several important theoretical and practical merits and implications. First, previous studies that aimed to separate subjective or idiosyncratic situation perceptions from more objective or consensual ones relied on written descriptions based on — possibly biased — situation cues (Rauthmann et al., 2015c; Sherman et al., 2013). This is the first study to examine individuals' idiosyncratic situation perceptions using ratings of informants that first-handedly observed the situation as it naturally unfolded. Including an observer of the situations student teachers encountered allowed us to disentangle five separate situation components that each contributed to explaining variance in student teachers' personality expressions. In addition, the large variability found in teachers' situation characteristics (and personality states) also according to observers may argue against previous claims that within-person variability only exists in the mind of the actor (see also the work by Fleeson \& Law, 2015).

Second and relatedly, the inclusion of informants has provided other valuable insights besides the decomposition of situation perceptions. Previous studies have, for example, noted that the exclusive reliance on self-reports in within-person research may lead to same-source bias and could influence substantive conclusions (e.g., Dalal et al., 2020). Using a multiinformant design, the present study afforded the opportunity to zoom in on replicable patterns across raters and to identify the possibility of common method bias in such studies. Our findings suggest that although we did observe several cross-rater effects, the presence of same-source bias (of both self- and other-ratings) may indeed be highly likely in experience sampling studies (see, e.g., Table 5). While many researchers (e.g., Horstmann et al., 2020) have raised awareness to such biases, our study is among the first to make this potential issue 
actually visible. However, an open question remains whether this is an actual bias because of the rating source, or whether this pattern may in fact reflect meaningful variance.

That is, already a century ago, Thorndike (1920) demonstrated that a number of very different traits (e.g., intelligence, leadership, physical qualities) were highly correlated in a sample of army officers, an effect better known today as the halo-effect. In brief, this is the phenomenon in which the presence of a desirable characteristic in a person leads to the automatic assumption that that individual will also possess other desirable characteristics (Nisbett \& Wilson, 1977). It is not unlikely that a similar effect may have been present at the state-level in the present study, resulting in a positive manifold in which desirable personality states and situation characteristics show high correlations both among and between each other. Similarly, the existence of a general factor of personality (Musek, 2007)—or more broadly speaking, some type of general positive evaluation factor-representing all socially desirable (personality) characteristics, could also have played a role in these substantial correlations. To summarize, while our study brought to the attention a pattern in which ratings by the same source are (highly) correlated, it remains unknown whether this is due to common method biases or whether this actually reflects true and useful variance.

Third, our findings may also have implications for our understanding and treatment of problems such as burnout, stress, and anxiety in teachers. For example, while student teachers scoring higher on trait Neuroticism behaved more insecure or tense in class (i.e., state Neuroticism), our findings also suggest that teachers' construal of Negativity in the situation may be linked to this behavior. This has important implications for the coaching of teachers in training and practicing teachers. That is, although it is possible to change one's personality traits volitionally and in an enduring way, this is no easy task (see, e.g., Baranski et al., 2020; Hudson \& Fraley, 2015; Stieger et al., 2021). Instead, modifying individuals' subjective and possibly biased interpretations of their environment may be more feasible, for example, by 
identifying those situation perceptions that may lead to maladaptive behaviors and developing cognitive strategies or thinking styles to modify those perceptions (Wood et al., 2019).

\section{Limitations and Prospects}

This research has some limitations that also point towards future lines of research. First, although an important contribution of the current study is its inclusion of informantreports of both situation characteristics and personality states, the study design allowed for the inclusion of only one rater juxta situm. Our conclusions are therefore limited in that they only demonstrate how student teachers' situation perceptions that are different from their supervisor's relate to momentary behaviors. Nevertheless, supervisors' situation perceptions may, of course, also be colored by their own idiosyncrasies. Future research should harness the advantages of the present research design, and could, for example, carry out similar research with (student) teachers in higher grade levels so that situations can be evaluated by a multitude of individuals juxta situm (i.e., the pupils). ${ }^{9}$

Second and relatedly, more research is needed to enable generalization of the present findings to, for example, other occupations or age groups (see, e.g., Noftle \& Gust, 2019). Our conclusions are limited to a relatively young sample of student teachers, who may interpret and respond differently to situational characteristics than teachers with more experience. For example, compared to more experienced teachers, student teachers have lower self-efficacy beliefs (Putman, 2012) and hold more concerns about their classroom management (Melnick \& Meister, 2008). Such individual differences may, of course, contribute to idiosyncratic situation perceptions. Future studies may therefore prioritize to extend the present self- and other-rated research to other work settings with a high level of

\footnotetext{
${ }^{9}$ Pupils in the present study were approximately 10 or 11 years old. Although they were included in the broader research and rated their teacher's momentary job performance, we considered them too young to rate the DIAMONDS/CAPTION dimensions in their current form. This may be an interesting avenue for future research.
} 
supervision, in order to examine the extent to which person-situation dynamics may be generalizable across different job characteristics, ages, and levels of experience.

Third, in order to minimize the intrusiveness of our study as much as possible, we scheduled the assessments during lunch break or after school and requested participants to rate items based on the previous hour. Critical readers may argue that this may have shifted the focus to more abstract episodes consisting of multiple situations (Rauthmann et al., 2015a), resulting in a report of the average behavior across this time interval instead (Breil et al., 2019, p. 20). However, the hour preceding the assessment encompassed mostly one lesson and thus should have been rather homogeneous in its cue and characteristic structure (fluctuations within that episode notwithstanding).

Fourth, due to the relatively limited variability in teachers' situations (i.e., the classroom setting with its implicit and explicit rules), restriction in variance may have led to more conservative estimates of the effects. This is consistent with the idea of fixed vs. random situations (Geiser et al., 2015; Horstmann, 2020). Fixed situations refer to situations in which it is - to a certain degree- known in what type of situation participants are in (e.g., a teaching situation), whereas random situations are interchangeable and are assumed to be sampled randomly from a universe of situations (Geiser et al., 2015). In other words, whereas situations in our study are somewhere in between fixed and random - they are all teaching situations (i.e., fixed), but within that context situations are assumed to be random-, situations generally experienced in daily life (e.g., socializing, doing household chores, commuting, etc.) can be seen as more random situations in which one can of course expect much more variability.

Fifth and finally, recent studies have examined the extent to which within-person fluctuations in both situational perception and personality states may overlap with fluctuations in affect (Horstmann et al., 2020; Horstmann \& Ziegler, 2019; Wilson et al., 
2017). Wilson et al. (2017), for example, demonstrated that situation variables predicted variance in personality states after accounting for fluctuations in affect, although only to a limited extent. More recently, Horstmann et al. (2020) found that personality traits, affect, and situation perception each contribute uniquely in explaining self-reported behavior (i.e., personality states). Taken together these findings suggest that although personality states and situation perception may correlate with affect, they are more than only affect. Nevertheless, given that there still are considerable overlaps, this may warrant extra attention in future research.

\section{Conclusions}

Including both self- and other-ratings in an experience sampling design, the present study examined the dynamics between personality traits, personality states, and situation characteristics in an educational context. Person-situation dynamics should merit significant attention in research but also in applied settings as they may have important implications for the performance, selection, and coaching of employees. This research yielded implications on both an applied and theoretical level—on the one hand, by examining questions that are of direct practical relevance and, on the other hand, by supporting theory development on within-person and situation processes on a broader level. We hope this innovative multi-rater experience sampling design incites further research on person-situation dynamics and invite extensions of similar research in other applied contexts as well. 


\section{References}

Arslan, R. C., Walther, M. P., \& Tata, C. S. (2020). formr: A study framework allowing for automated feedback generation and complex longitudinal experience-sampling studies using R. Behavior Research Methods, 52(1), 376-387. https://doi.org/10.3758/s13428$\underline{019-01236-y}$

Baranski, E., Gray, J., Morse, P., \& Dunlop, W. (2020). From desire to development? A multi-sample, idiographic examination of volitional personality change. Journal of Research in Personality, 85. https://doi.org/10.1016/j.jrp.2019.103910

Bates, D., Mächler, M., Bolker, B., \& Walker, S. (2015). Fitting linear mixed-effects models using lme4. Journal of Statistical Software, 67(1), 1-48. https://doi.org/10.18637/jss.v067.i01

Ben-Shachar, M. S., Makowski, D., \& Lüdecke, D. (2020). Compute and interpret indices of effect size. Cran R package. https://github.com/easystats/effectsize

Breil, S. M., Geukes, K., Wilson, R. E., Nestler, S., Vazire, S., \& Back, M. D. (2019). Zooming into real-life extraversion - how personality and situation shape sociability in social interactions. Collabra: Psychology, 5(1). https://doi.org/10.1525/collabra.170

Cho, Y., \& Shim, S. S. (2013). Predicting teachers' achievement goals for teaching: The role of perceived school goal structure and teachers' sense of efficacy. Teaching and Teacher Education, 32, 12-21. https://doi.org/10.1016/j.tate.2012.12.003

Dalal, R. S., Alaybek, B., \& Lievens, F. (2020). Within-person job performance variability over short timeframes: Theory, empirical research, and practice. Annual Review of Organizational Psychology and Organizational Behavior, 7(1), 421-449. https://doi.org/10.1146/annurev-orgpsych-012119-045350 
de Raad, B. (2004). Situations that matter to personality. In A. Eliasz, S. E. Hampson, \& B. d. Raad (Eds.), Advances in personality psychology (Vol. 2, pp. 179-204). Psychology Press. https://doi.org/10.4324/9780203000953

de Raad, B., \& Doddema-Winsemius, M. (2006). De Big 5 persoonlijkheidsfactoren. Uitgeverij Nieuwezijds.

Denissen, J. J., Geenen, R., van Aken, M. A., Gosling, S. D., \& Potter, J. (2008). Development and validation of a Dutch translation of the Big Five Inventory (BFI). Journal of Personality Assessment, 90(2), 152-157. https://doi.org/10.1080/00223890701845229

DeYoung, C. G. (2015). Openness/intellect: A dimension of personality reflecting cognitive exploration. In M. Mikulincer, P. R. Shaver, M. L. Cooper, \& R. J. Larsen (Eds.), APA handbook of personality and social psychology, Volume 4: Personality processes and individual differences. (pp. 369-399). American Psychological Association. https://doi.org/10.1037/14343-017

Edwards, J. A., \& Templeton, A. (2005). The structure of perceived qualities of situations. European Journal of Social Psychology, 35(6), 705-723. https://doi.org/10.1002/ejsp.271

Finnigan, K. M., \& Vazire, S. (2018). The incremental validity of average state self-reports over global self-reports of personality. Journal of Personality and Social Psychology, 115(2), 321-337. https://doi.org/10.1037/pspp0000136

Fleeson, W., \& Jayawickreme, E. (2015). Whole trait theory. Journal of Research in Personality, 56, 82-92. https://doi.org/10.1016/j.jrp.2014.10.009

Fleeson, W., \& Law, M. K. (2015). Trait enactments as density distributions: The role of actors, situations, and observers in explaining stability and variability. Journal of 
Personality and Social Psychology, 109(6), 1090-1104.

https://doi.org/10.1037/a0039517

Funder, D. (2016). Taking situations seriously: The Situation Construal Model and the Riverside Situational Q-sort. Current Directions in Psychological Science, 25(3), 203208. https://doi.org/10.1177/0963721416635552

Furr, R. M., \& Funder, D. (2018). Persons, situations, and person-situation interactions. In O. P. John \& R. W. Robins (Eds.), Handbook of personality: Theory and research (4th ed.). Guilford.

Geiser, C., Litson, K., Bishop, J., Keller, B. T., Burns, G. L., Servera, M., \& Shiffman, S. (2015). Analyzing person, situation and person x situation interaction effects: Latent state-trait models for the combination of random and fixed situations. Psychological Methods, 20(2), 165-192. https://doi.org/10.1037/met0000026

Geldhof, G. J., Preacher, K. J., \& Zyphur, M. J. (2014). Reliability estimation in a multilevel confirmatory factor analysis framework. Psychological Methods, 19(1), 72-91. https://doi.org/10.1037/a0032138

Green, J. P., Dalal, R. S., Swigart, K. L., Bleiberg, M. A., Wallace, D. M., \& Hargrove, A. K. (2018). Personality consistency and situational influences on behavior. Journal of Management, 45(8), 3204-3234. https://doi.org/10.1177/0149206318781950

Hogan, R. (2009). Much ado about nothing: The person-situation debate. Journal of Research in Personality, 43(2), 249. https://doi.org/10.1016/j.jrp.2009.01.022

Hong, R. Y., Chan, W. Y., \& Lim, J. Y. R. (2020). Pathological personality traits and the experience of daily situations. Clinical Psychological Science, 8(2), 333-342. https://doi.org/10.1177/2167702619894902 
Horstmann, K. T. (2020). Experience sampling and daily diary studies: Basic concepts, designs, and challenges. In J. F. Rauthmann (Ed.), The handbook of personality dynamics and processes. Academic Press.

Horstmann, K. T., \& Rauthmann, J. F. (in preparation). How many states make a trait? A comprehensive meta-analysis of experience sampling studies. https://osf.io/jvqu3/

Horstmann, K. T., Rauthmann, J. F., \& Sherman, R. A. (2018). The measurement of situational influences. In V. Zeigler-Hill \& T. K. Shackelford (Eds.), The Sage handbook of personality and individual differences. Sage.

Horstmann, K. T., Rauthmann, J. F., Sherman, R. A., \& Ziegler, M. (2020). Unveiling an exclusive link: Predicting behavior with personality, situation perception, and affect in a preregistered experience sampling study. Journal of Personality and Social Psychology. https://doi.org/10.1037/pspp0000357

Horstmann, K. T., \& Ziegler, M. (2016). Situational perception: Its theoretical foundation, assessment, and links to personality. In U. Kumar (Ed.), The Wiley Handbook of Personality Assessment (pp. 31-43). Wiley Blackwell.

Horstmann, K. T., \& Ziegler, M. (2019). Situational perception and affect: Barking up the wrong tree? Personality and Individual Differences, 136, 132-139. https://doi.org/10.1016/j.paid.2018.01.020

Huang, J. L., \& Ryan, A. M. (2011). Beyond personality traits: A study of personality states and situational contingencies in customer service jobs. Personnel Psychology, 64(2), 451-488. https://doi.org/10.1111/j.1744-6570.2011.01216.x

Hudson, N. W., \& Fraley, R. C. (2015). Volitional personality trait change: Can people choose to change their personality traits? Journal of Personality and Social Psychology, 109(3), 490-507. https://doi.org/10.1037/pspp0000021 
Jones, A. B., Brown, N. A., Serfass, D. G., \& Sherman, R. A. (2017). Personality and density distributions of behavior, emotions, and situations. Journal of Research in Personality, 69, 225-236. https://doi.org/10.1016/j.jrp.2016.10.006

Judge, T. A., \& Zapata, C. P. (2015). The person-situation debate revisited: Effect of situation strength and trait activation on the validity of the Big Five personality traits in predicting job performance. Academy of Management Journal, 58(4), 1149-1179. https://doi.org/10.5465/amj.2010.0837

Kim, L. E., Jörg, V., \& Klassen, R. M. (2019). A meta-analysis of the effects of teacher personality on teacher effectiveness and burnout. Educational Psychology Review, 31(1), 163-195. https://doi.org/10.1007/s10648-018-9458-2

Klassen, R. M., \& Kim, L. E. (2017). Assessing critical attributes of prospective teachers: Implications for selection into initial teacher education programs. In D. W. Putwain \& K. Smart (Eds.), British Journal of Educational Psychology Monograph Series II: Psychological Aspects of Education (pp. 5-22). Wiley.

Klumb, P., Elfering, A., \& Herre, C. (2009). Ambulatory assessment in Industrial/Organizational Psychology. European Psychologist, 14(2), 120-131. https://doi.org/10.1027/1016-9040.14.2.120

Klusmann, U., Kunter, M., Trautwein, U., Lüdtke, O., \& Baumert, J. (2008a). Engagement and emotional exhaustion in teachers: Does the school context make a difference? Applied Psychology, 57(s1), 127-151. https://doi.org/10.1111/j.1464$\underline{0597.2008 .00358 . \mathrm{x}}$

Klusmann, U., Kunter, M., Trautwein, U., Lüdtke, O., \& Baumert, J. (2008b). Teachers' occupational well-being and quality of instruction: The important role of selfregulatory patterns. Journal of Educational Psychology, 100(3), 702-715. https://doi.org/10.1037/0022-0663.100.3.702 
Lorah, J. (2018). Effect size measures for multilevel models: definition, interpretation, and TIMSS example. Large-scale Assessments in Education, 6(1). https://doi.org/10.1186/s40536-018-0061-2

McCormick, B. W., Reeves, C. J., Downes, P. E., Li, N., \& Ilies, R. (2020). Scientific contributions of within-person research in management: Making the juice worth the squeeze. Journal of Management, 46(2), 321-350. https://doi.org/10.1177/0149206318788435

McCrae, R. R. (1987). Creativity, divergent thinking, and openness to experience. Journal of Personality and Social Psychology, 52(6), 1258-1265. https://doi.org/10.1037/0022$\underline{3514.52 .6 .1258}$

McDonald, R. P. (1999). Test theory: A unified treatment. Erlbaum.

Melnick, S. A., \& Meister, D. G. (2008). A comparison of beginning and experienced teachers' concerns. Educational Research Quarterly, 31(3), 39-56.

Molenaar, P. C. M. (2004). A manifesto on psychology as idiographic science: Bringing the person back Into scientific psychology, this time forever. Measurement: Interdisciplinary Research \& Perspective, 2(4), 201-218. https://doi.org/10.1207/s15366359mea0204_1

Morse, P., Sauerberger, K. S., Todd, E., \& Funder, D. (2015a). Relationships among personality, situational construal and social outcomes. European Journal of Personality, 29, 97-106. https://doi.org/10.1002/per.1987

Morse, P., Sweeny, K., \& Legg, A. M. (2015b). A situational construal approach to healthcare experiences. Social Science \& Medicine, 138, 170-178. https://doi.org/10.1016/j.socscimed.2015.06.005 
Murayama, K., Goetz, T., Malmberg, L.-E., Pekrun, R., Tanaka, A., \& Martin, A. J. (2017). Within-person analysis in educational psychology: Importance and illustrations. British Journal of Educational Psychology Monograph Series II, 12, 71-87.

Murray, H. A. (1938). Explorations in personality. Oxford University Press.

Musek, J. (2007). A general factor of personality: Evidence for the Big One in the five-factor model. Journal of Research in Personality, 41(6), 1213-1233. https://doi.org/10.1016/j.jrp.2007.02.003

Nakagawa, S., \& Schielzeth, H. (2013). A general and simple method for obtaining R2 from generalized linear mixed-effects models. Methods in Ecology and Evolution, 4(2), 133-142. https://doi.org/10.1111/j.2041-210x.2012.00261.x

Nezlek, J. B. (2007). A multilevel framework for understanding relationships among traits, states, situations and behaviours. European Journal of Personality, 21(6), 789-810. https://doi.org/10.1002/per.640

Nezlek, J. B. (2017). A practical guide to understanding reliability in studies of within-person variability. Journal of Research in Personality, 69, 149-155. https://doi.org/10.1016/j.jrp.2016.06.020

Nisbett, R. E., \& Wilson, T. D. (1977). The halo effect: Evidence for unconscious alteration of judgments. Journal of Personality and Social Psychology, 35(4), 250-256. https://doi.org/10.1037/0022-3514.35.4.250

Noftle, E. E., \& Gust, C. J. (2019). Age differences across adulthood in interpretations of situations and situation-behaviour contingencies for Big Five states. European Journal of Personality, 33(3), 279-297. https://doi.org/10.1002/per.2203

Nusbaum, E. C., Silvia, P. J., \& Beaty, R. E. (2017). Ha ha? Assessing individual differences in humor production ability. Psychology of Aesthetics, Creativity, and the Arts, 11(2), 231-241. https://doi.org/10.1037/aca0000086 
Parrigon, S., Woo, S. E., Tay, L., \& Wang, T. (2017). CAPTION-ing the situation: A lexically-derived taxonomy of psychological situation characteristics. Journal of Personality and Social Psychology, 112(4), 642-681.

https://doi.org/10.1037/pspp0000111

Podsakoff, P. M., MacKenzie, S. B., Lee, J. Y., \& Podsakoff, N. P. (2003). Common method biases in behavioral research: A critical review of the literature and recommended remedies. Journal of Applied Psychology, 88(5), 879-903.

https://doi.org/10.1037/0021-9010.88.5.879

Putman, S. M. (2012). Investigating teacher efficacy: Comparing preservice and inservice teachers with different levels of experience. Action in Teacher Education, 34(1), 2640. https://doi.org/10.1080/01626620.2012.642285

R Core Team. (2020). R: A language and environment for statistical computing. In $\mathrm{R}$ Foundation for Statistical Computing. https://www.R-project.org/

Rauthmann, J., Horstmann, K. T., \& Sherman, R. (2020a). The psychological characteristics of situations: Towards an integrated taxonomy. In J. F. Rauthmann, R. A. Sherman, \& D. C. Funder (Eds.), The Oxford Handbook of Psychological Situations. Oxford University Press.

Rauthmann, J., \& Sherman, R. (2019). Toward a research agenda for the study of situation perceptions: A variance componential framework. Personality and Social Psychology Review, 23(3), 238-266. https://doi.org/10.1177/1088868318765600

Rauthmann, J. F. (2015). Structuring situational information. European Psychologist, 20(3), 176-189. https://doi.org/10.1027/1016-9040/a000225

Rauthmann, J. F., Gallardo-Pujol, D., Guillaume, E. M., Todd, E., Nave, C. S., Sherman, R. A., Ziegler, M., Jones, A. B., \& Funder, D. C. (2014). The Situational Eight DIAMONDS: a taxonomy of major dimensions of situation characteristics. Journal of 
Personality and Social Psychology, 107(4), 677-718. https://doi.org/10.1037/a0037250

Rauthmann, J. F., Jones, A. B., \& Sherman, R. A. (2016). Directionality of person-situation transactions: Are there spillovers among and between situation experiences and personality states? Personality and Social Psychology Bulletin, 42(7), 893-909. https://doi.org/10.1177/0146167216647360

Rauthmann, J. F., \& Sherman, R. A. (2016). Ultra brief measures for the Situational Eight DIAMONDS domains. European Journal of Psychological Assessment, 32(2), 165 174. https://doi.org/10.1027/1015-5759/a000245

Rauthmann, J. F., \& Sherman, R. A. (2018). The description of situations: Towards replicable domains of psychological situation characteristics. Journal of Personality and Social Psychology, 114(3), 482-488. https://doi.org/10.1037/pspp0000162

Rauthmann, J. F., \& Sherman, R. A. (2020). The situation of situation research: Knowns and unknowns. Current Directions in Psychological Science, 473-480. https://doi.org/10.1177/0963721420925546

Rauthmann, J. F., Sherman, R. A., \& Funder, D. C. (2015a). New horizons in research on psychological situations and environments. European Journal of Personality, 29(3), 382-432. https://doi.org/10.1002/per.2005

Rauthmann, J. F., Sherman, R. A., \& Funder, D. C. (2015b). Principles of situation research: Towards a better understanding of psychological situations. European Journal of Personality, 29, 363-381. https://doi.org/10.1002/per.1994

Rauthmann, J. F., Sherman, R. A., \& Funder, D. C. (Eds.). (2020b). The Oxford handbook of psychological situations. Oxford University Press.

Rauthmann, J. F., Sherman, R. A., Nave, C. S., \& Funder, D. C. (2015c). Personality-driven situation experience, contact, and construal: How people's personality traits predict 
characteristics of their situations in daily life. Journal of Research in Personality, 55, 98-111. https://doi.org/10.1016/j.jrp.2015.02.003

Rintala, A., Wampers, M., Myin-Germeys, I., \& Viechtbauer, W. (2019). Response compliance and predictors thereof in studies using the experience sampling method. Psychological Assessment, 31(2), 226-235. https://doi.org/10.1037/pas0000662

Schmidt, J., Klusmann, U., Lüdtke, O., Möller, J., \& Kunter, M. (2017). What makes good and bad days for beginning teachers? A diary study on daily uplifts and hassles. Contemporary Educational Psychology, 48, 85-97. https://doi.org/10.1016/j.cedpsych.2016.09.004

Serfass, D. G., \& Sherman, R. A. (2013). Personality and perceptions of situations from the Thematic Apperception Test. Journal of Research in Personality, 47, 708-718. https://doi.org/10.1016/j.jrp.2013.06.007

Sherman, R. A., Nave, C. S., \& Funder, D. (2013). Situational construal is related to personality and gender. Journal of Research in Personality, 47, 1-14. https://doi.org/10.1016/j.jrp.2012.10.008

Sherman, R. A., Nave, C. S., \& Funder, D. C. (2010). Situational similarity and personality predict behavioral consistency. Journal of Personality and Social Psychology, 99(2), 330-343. https://doi.org/10.1037/a0019796

Sherman, R. A., Rauthmann, J. F., Brown, N. A., Serfass, D. G., \& Jones, A. B. (2015). The independent effects of personality and situations on real-time expressions of behavior and emotion. Journal of Personality and Social Psychology, 109(5), 872-888. https://doi.org/10.1037/pspp0000036

Skaalvik, E. M., \& Skaalvik, S. (2009). Does school context matter? Relations with teacher burnout and job satisfaction. Teaching and Teacher Education, 25(3), 518-524. https://doi.org/10.1016/j.tate.2008.12.006 
Snijders, T. A. B., \& Bosker, R. J. (2012). Multilevel analysis: An introduction to basic and advanced multilevel modeling. Sage Publishing.

Stieger, M., Fluckiger, C., Ruegger, D., Kowatsch, T., Roberts, B. W., \& Allemand, M. (2021). Changing personality traits with the help of a digital personality change intervention. Proceedings of the National Academy of Sciences, 118(8), e2017548118. https://doi.org/10.1073/pnas.2017548118

Sun, J., Rhemtulla, M., \& Vazire, S. (2020). Eavesdropping on missing data: What are university students doing when they miss experience sampling reports? Personality and Social Psychology Bulletin, 146167220964639. https://doi.org/10.1177/0146167220964639

Sun, J., \& Vazire, S. (2019). Do people know what they're like in the moment? Psychological Science, 30(3), 405-414. https://doi.org/10.1177/0956797618818476

Thorndike, E. L. (1920). A constant error in psychological ratings. Journal of Applied Psychology, 4(1), 25-29. https://doi.org/10.1037/h0071663

Tsai, Y.-M., Kunter, M., Lüdtke, O., Trautwein, U., \& Ryan, R. M. (2008). What makes lessons interesting? The role of situational and individual factors in three school subjects. Journal of Educational Psychology, 100(2), 460-472. https://doi.org/10.1037/0022-0663.100.2.460

Wilson, R. E., Thompson, R. J., \& Vazire, S. (2017). Are fluctuations in personality states more than fluctuations in affect? Journal of Research in Personality, 69, 110-123. https://doi.org/10.1016/j.jrp.2016.06.006

Wilt, J., \& Revelle, W. (2019). The Big Five, everyday contexts and activities, and affective experience. Personality and Individual Differences, 136, 140-147.

https://doi.org/10.1016/j.paid.2017.12.032 
Wood, R. E., Beckmann, N., Birney, D. P., Beckmann, J. F., Minbashian, A., \& Chau, R. (2019). Situation contingent units of personality at work. Personality and Individual Differences, 136, 113-121. https://doi.org/10.1016/j.paid.2018.01.026

Wrzus, C., Wagner, G. G., \& Riediger, M. (2016). Personality-situation transactions from adolescence to old age. Journal of Personality and Social Psychology, 110(5), 782799. https://doi.org/10.1037/pspp0000054

Ziegler, M., Horstmann, K. T., \& Ziegler, J. (2019). Personality in situations: Going beyond the OCEAN and introducing the Situation Five. Psychological Assessment, 31(4), 567-580. https://doi.org/10.1037/pas0000654 


\section{Data Accessibility Statement}

The study materials, data and analysis scripts used for this article can be accessed at https://osf.io/p642h/. 
PERSON-SITUATION DYNAMICS IN EDUCATIONAL CONTEXTS

\section{Table 1}

Predicted Associations Between Personality Traits/States and Situation Characteristics

\begin{tabular}{|c|c|c|c|c|c|c|c|}
\hline & $\begin{array}{c}\text { Duty/ } \\
\text { Importance }\end{array}$ & $\begin{array}{c}\text { Intellect/ } \\
\text { Complexity }\end{array}$ & $\begin{array}{c}\text { Adversity/ } \\
\text { Negative Valence }\end{array}$ & $\begin{array}{c}\text { Positivity/ } \\
\text { Positive Valence }\end{array}$ & $\begin{array}{l}\text { Negativity } \\
\text { Adversity }\end{array}$ & Typicality & Humor \\
\hline Conscientiousness & + & & & & & & \\
\hline Agreeableness & & & - & + & - & & \\
\hline Neuroticism & & & + & - & + & & \\
\hline
\end{tabular}


Table 2

Descriptive Characteristics

\begin{tabular}{|c|c|c|c|c|c|c|c|c|c|c|c|c|c|}
\hline \multirow[t]{2}{*}{ Variables } & \multicolumn{5}{|c|}{ Self-rated (Teachers) } & \multicolumn{5}{|c|}{ Other-rated (Supervisors) } & \multicolumn{3}{|c|}{ Joined } \\
\hline & $M$ & $S D$ & $\mathrm{ICC}$ & $\omega_{\mathrm{BP}}$ & $\omega \mathrm{WP}$ & $M$ & $S D$ & ICC & $\omega_{\mathrm{BP}}$ & $\omega \mathrm{WP}$ & $M$ & $S D$ & $\mathrm{ICC}$ \\
\hline \multicolumn{14}{|l|}{ Personality traits } \\
\hline Openness & 3.43 & 0.49 & - & - & - & - & - & - & - & - & - & - & - \\
\hline Conscientiousness & 3.67 & 0.60 & - & - & - & - & - & - & - & - & - & - & - \\
\hline Extraversion & 3.58 & 0.59 & - & - & - & - & - & - & - & - & - & - & - \\
\hline Agreeableness & 3.87 & 0.47 & - & - & - & - & - & - & - & - & - & - & - \\
\hline Neuroticism & 3.18 & 0.70 & - & - & - & - & - & - & - & - & - & - & - \\
\hline \multicolumn{14}{|l|}{ Personality states } \\
\hline Openness & 3.76 & 0.79 & .29 & .78 & .60 & 3.85 & 0.88 & .47 & .95 & .60 & - & - & - \\
\hline Conscientiousness & 3.97 & 0.65 & .43 & .79 & .43 & 4.10 & 0.71 & .48 & .87 & .56 & - & - & - \\
\hline Extraversion & 3.95 & 0.65 & .35 & .55 & .47 & 3.82 & 0.76 & .51 & .74 & .35 & - & - & - \\
\hline Agreeableness & 4.42 & 0.49 & .44 & .71 & .39 & 4.59 & 0.46 & .53 & .76 & .23 & - & - & - \\
\hline Neuroticism & 2.29 & 0.86 & .36 & .85 & .67 & 2.25 & 0.87 & .41 & .94 & .67 & - & - & - \\
\hline \multicolumn{14}{|l|}{ Situation experience } \\
\hline Duty & 3.96 & 0.77 & .18 & - & - & 3.96 & 0.81 & .36 & - & - & - & - & - \\
\hline Intellect & 3.63 & 0.87 & .20 & - & - & 3.79 & 0.83 & .39 & - & - & - & - & - \\
\hline Adversity & 2.69 & 1.29 & .33 & - & - & 2.96 & 1.20 & .42 & - & - & - & - & - \\
\hline Positivity & 3.74 & 0.82 & .18 & - & - & 3.86 & 0.84 & .33 & - & - & - & - & - \\
\hline Negativity & 1.68 & 0.90 & .32 & - & - & 1.52 & 0.80 & .36 & - & - & - & - & - \\
\hline Typicality & 3.96 & 1.11 & .32 & - & - & 4.31 & 0.93 & .28 & - & - & - & - & - \\
\hline Humor & 2.72 & 1.07 & .27 & - & - & 2.32 & 1.04 & .36 & - & - & - & - & - \\
\hline \multicolumn{14}{|l|}{ Situation construal } \\
\hline Duty & 0.00 & 0.75 & .14 & - & - & 0.00 & 0.74 & .31 & - & - & - & - & - \\
\hline Intellect & 0.00 & 0.82 & .21 & - & - & 0.00 & 0.78 & .32 & - & - & - & - & - \\
\hline Adversity & 0.00 & 1.24 & .36 & - & - & 0.00 & 1.16 & .43 & - & - & - & - & - \\
\hline Positivity & 0.00 & 0.75 & .16 & - & - & 0.00 & 0.78 & .32 & - & - & - & - & - \\
\hline Negativity & 0.00 & 0.88 & .30 & - & - & 0.00 & 0.73 & .30 & - & - & - & - & - \\
\hline Typicality & 0.00 & 1.02 & .27 & - & - & 0.00 & 0.90 & .27 & - & - & - & - & - \\
\hline Humor & 0.00 & 1.04 & .33 & - & - & 0.00 & 1.01 & .37 & - & - & - & - & - \\
\hline
\end{tabular}




\begin{tabular}{|c|c|c|c|c|c|c|c|c|c|c|c|c|c|}
\hline Situation cons & & & & & & & & & & & & & \\
\hline Duty & - & - & - & - & - & - & - & - & - & - & -0.01 & 0.43 & .30 \\
\hline Intellect & - & - & - & - & - & - & - & - & - & - & 0.00 & 0.36 & .36 \\
\hline Adversity & - & - & - & - & - & - & - & - & - & - & 0.04 & 0.87 & .44 \\
\hline Positivity & - & - & - & - & - & - & - & - & - & - & 0.00 & 0.43 & .29 \\
\hline Negativity & - & - & - & - & - & - & - & - & - & - & 0.00 & 0.50 & .39 \\
\hline Typicality & - & - & - & - & - & - & - & - & - & - & 0.03 & 0.55 & .30 \\
\hline Humor & - & - & - & - & - & - & - & - & - & - & -0.04 & 0.64 & .35 \\
\hline
\end{tabular}

Note. $M=$ mean; $S D=$ standard deviation; ICC = intraclass correlation coefficient; $\omega_{\mathrm{BP}}=$ between-person omega reliability coefficient $\omega_{\mathrm{WP}}=$ within-person omega reliability coefficient. $N=173$ student teachers $(n=2,244-2,261$ observations); $N=94$ supervisors $(n=$ 1,110-1,122 observations). All items used a 5-point Likert-type response scale. 
Table 3

Between-Person Correlations Between Personality Traits and Situation Characteristics (Question 1)

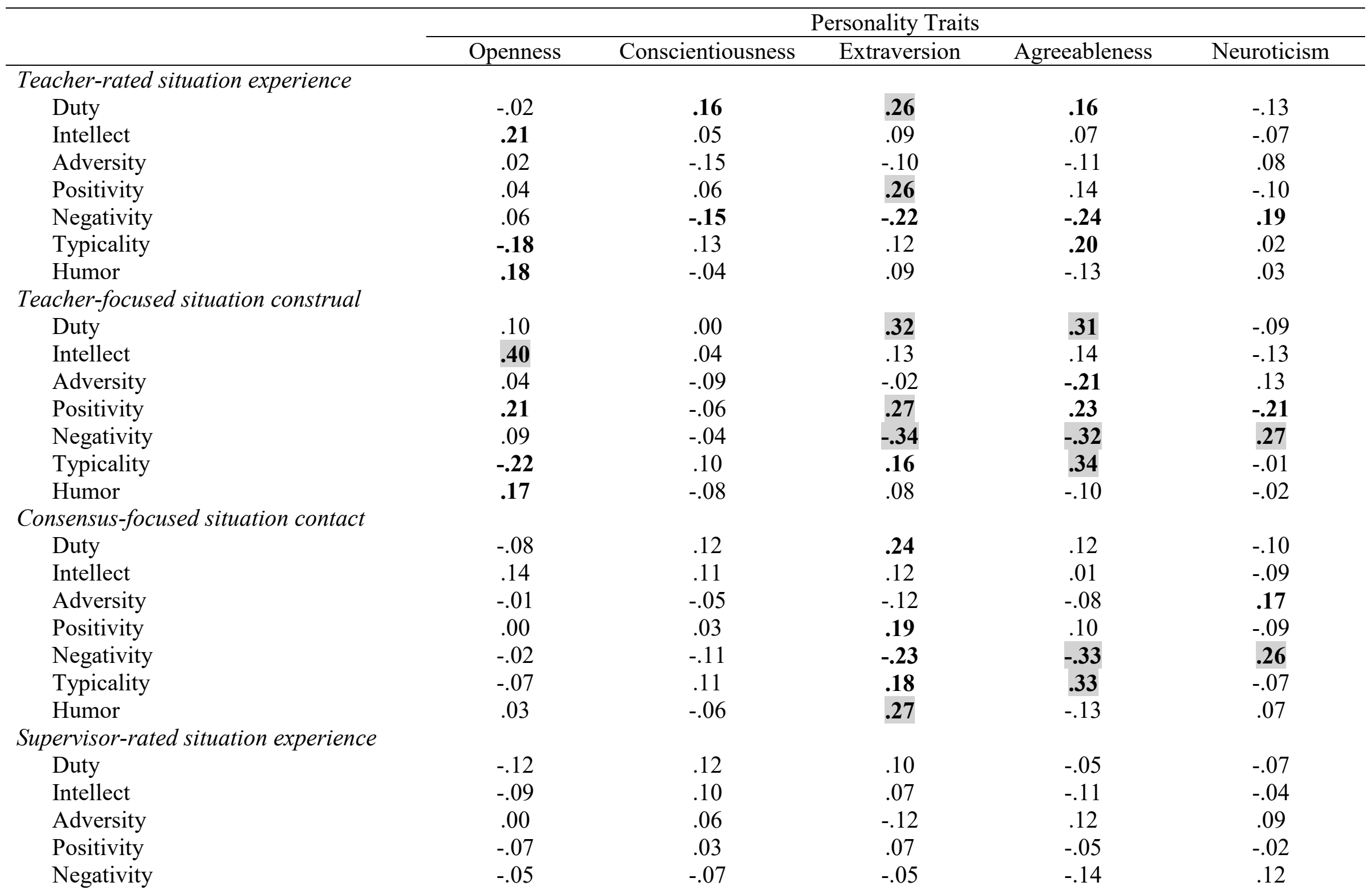




\begin{tabular}{|c|c|c|c|c|c|}
\hline Typicality & .08 & .01 & .05 & .05 & -.12 \\
\hline Humor & -.12 & -.01 & .28 & -.01 & .10 \\
\hline upervisor-fo & & & & & \\
\hline Duty & -.18 & .14 & -.01 & -.13 & -.03 \\
\hline Intellect & -.19 & .10 & .04 & -.12 & .00 \\
\hline Adversity & -.06 & .04 & -.14 & .14 & .08 \\
\hline Positivity & -.18 & .09 & -.02 & -.10 & .08 \\
\hline Negativity & -.12 & -.10 & .07 & -.08 & .04 \\
\hline Typicality & .21 & .03 & .06 & .04 & -.10 \\
\hline Humor & -.15 & .01 & .25 & -.05 & .11 \\
\hline
\end{tabular}

Note. $N=173$ student teachers; $N=94$ supervisors. Correlation coefficients in bold are statistically significant at the $p<.05$ level. Correlation coefficients in bold and gray-shaded are statistically significant at the $p<.001$ level. 


\section{Table 4}

Teachers' Self-Reported Personality Traits Predicting Situation Characteristics (Question 1)

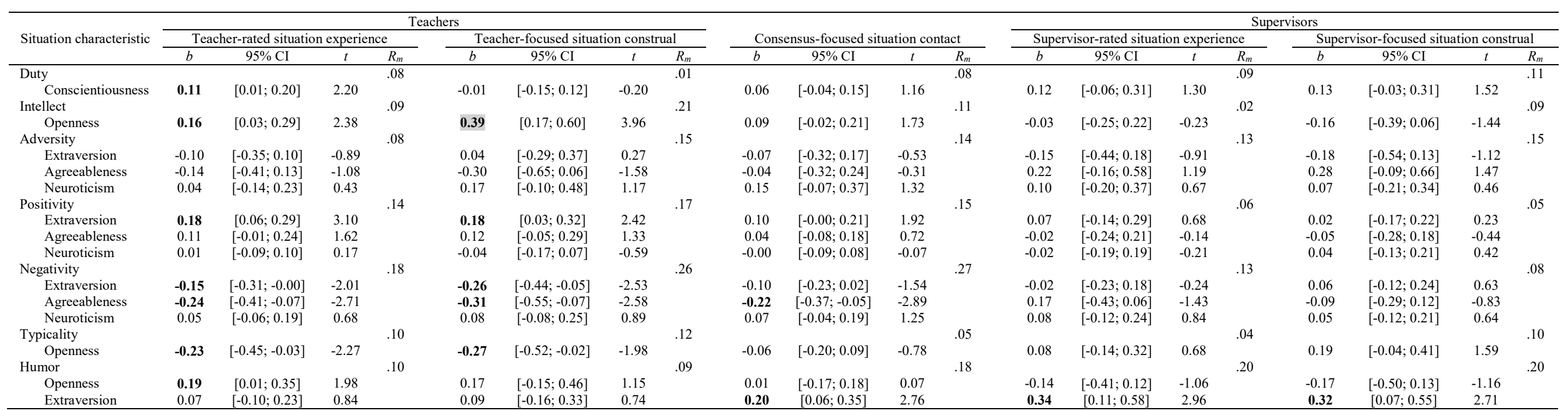

Note. $b=$ unstandardized multilevel regression coefficient; $95 \% \mathrm{CI}=95 \%$ confidence interval, $R_{m}=$ marginal multiple $R$ (Nakagawa \& Schielzeth, 2013 ).

Personality trait scores were grand mean centered. Regression coefficients in bold are statistically significant at the $p<.05$ level. Regression coefficients in bold and gray-shaded are statistically significant at the $p<.001$ level. 
Table 5

Within-Person Correlations Between Personality States and Situation Characteristics (Question 2)

\begin{tabular}{|c|c|c|c|c|c|c|c|c|c|c|}
\hline & \multicolumn{5}{|c|}{ Self-rated (Teachers) } & \multicolumn{5}{|c|}{ Other-rated (Supervisors) } \\
\hline & $\mathrm{O}$ & $\mathrm{C}$ & $E$ & A & $\mathrm{N}$ & $\mathrm{O}$ & $\mathrm{C}$ & $\mathrm{E}$ & A & $\mathrm{N}$ \\
\hline \multicolumn{11}{|c|}{ Teacher-rated situation experience } \\
\hline Duty & .35 & .34 & .38 & .35 & -.40 & .08 & .09 & .09 & .07 & -.12 \\
\hline Intellect & .17 & .24 & .18 & .18 & -.19 & -.02 & .04 & .01 & .00 & -.06 \\
\hline Adversity & -.09 & -.16 & -.13 & -.23 & .17 & .02 & .00 & -.03 & .01 & .07 \\
\hline Positivity & .32 & .35 & .38 & .33 & -.41 & .07 & .16 & .11 & .11 & -.16 \\
\hline Negativity & -.25 & -.29 & -.31 & -.33 & .43 & -.09 & -.16 & -.10 & -.10 & .17 \\
\hline Typicality & -.01 & .11 & .08 & .15 & -.09 & .02 & .07 & .00 & .08 & -.12 \\
\hline Humor & .36 & .14 & .29 & .18 & -.27 & .18 & .08 & .14 & .09 & -.11 \\
\hline \multicolumn{11}{|c|}{ Teacher-focused situation construal } \\
\hline Duty & .35 & .32 & .39 & .26 & -.32 & -.01 & .00 & .03 & .02 & -.02 \\
\hline Intellect & .15 & .22 & .17 & .11 & -.15 & -.08 & -.02 & -.05 & -.01 & -.01 \\
\hline Adversity & -.11 & -.12 & -.13 & -.20 & .15 & .00 & -.01 & -.04 & .02 & .06 \\
\hline Positivity & .31 & .32 & .43 & .32 & -.37 & -.01 & .07 & .04 & .04 & -.06 \\
\hline Negativity & -.22 & -.26 & -.29 & -.29 & .33 & -.03 & -.07 & -.02 & -.03 & .08 \\
\hline Typicality & .04 & .13 & .14 & .15 & -.12 & .01 & .04 & -.01 & .07 & -.10 \\
\hline Humor & .33 & .12 & .29 & .21 & -.25 & .13 & .07 & .10 & .08 & -.07 \\
\hline \multicolumn{11}{|c|}{ Consensus-focused situation contact } \\
\hline Duty & .37 & .31 & .38 & .32 & -.38 & .25 & .27 & .22 & .15 & -.29 \\
\hline Intellect & .16 & .23 & .19 & .13 & -.20 & .15 & .21 & .14 & .03 & -.17 \\
\hline Adversity & -.08 & -.12 & -.10 & -.18 & .14 & .02 & -.01 & -.03 & .02 & .08 \\
\hline Positivity & .32 & .31 & .37 & .33 & -.41 & .23 & .33 & .25 & .19 & -.31 \\
\hline Negativity & -.30 & -.28 & -.37 & -.34 & .42 & -.19 & -.29 & -.23 & -.22 & .30 \\
\hline Typicality & .02 & .14 & .12 & .17 & -.14 & .03 & .13 & .03 & .10 & -.13 \\
\hline Humor & .35 & .13 & .32 & .24 & -.26 & .28 & .13 & .26 & .11 & -.21 \\
\hline \multicolumn{11}{|c|}{ Supervisor-rated situation experience } \\
\hline Duty & .17 & .12 & .15 & .17 & -.20 & .38 & .34 & .28 & .23 & -.36 \\
\hline Intellect & .07 & .09 & .09 & .06 & -.11 & .32 & .32 & .23 & .09 & -.22 \\
\hline Adversity & .02 & -.04 & .00 & -.03 & .02 & .05 & .00 & .01 & .01 & .04 \\
\hline Positivity & .14 & .13 & .12 & .14 & -.19 & .38 & .37 & .31 & .23 & -.37 \\
\hline Negativity & -.17 & -.13 & -.21 & -.18 & .23 & -.28 & -.32 & -.32 & -.28 & .34 \\
\hline
\end{tabular}




\begin{tabular}{|c|c|c|c|c|c|c|c|c|c|c|}
\hline Typicality & -.02 & .05 & -.01 & .06 & -.07 & .08 & .18 & .13 & .11 & -.11 \\
\hline Humor & .16 & .07 & .18 & .13 & -.12 & .30 & .11 & .26 & .08 & -.24 \\
\hline \multicolumn{11}{|c|}{ upervisor-focused situation construal } \\
\hline Duty & .04 & .01 & .01 & .08 & -.09 & .30 & .32 & .23 & .16 & -.32 \\
\hline Intellect & .04 & .04 & .05 & .04 & -.09 & .28 & .28 & .23 & .06 & -.20 \\
\hline Adversity & .04 & .00 & .04 & .03 & -.02 & .03 & .00 & .01 & .01 & .02 \\
\hline Positivity & .03 & .01 & -.03 & .03 & -.08 & .29 & .32 & .25 & .18 & -.31 \\
\hline Negativity & -.09 & -.04 & -.10 & -.07 & .11 & -.18 & -.25 & -.24 & -.21 & .26 \\
\hline Typicality & -.02 & .03 & -.02 & .04 & -.05 & .03 & .15 & .06 & .06 & -.07 \\
\hline Humor & .08 & .03 & .10 & .08 & -.05 & .22 & .09 & .22 & .05 & -.20 \\
\hline
\end{tabular}

Note. $n=2,244-2,261$ self-reports; $n=1,110-1,122$ other-reports. For approximately $n=790$ of these observations, ratings of both teacher and supervisor were available. $\mathrm{O}=$ Openness, $\mathrm{C}=$ Conscientiousness, $\mathrm{E}=$ Extraversion, $\mathrm{A}=$ Agreeableness, $\mathrm{N}=\mathrm{Neuroticism}$. Correlation coefficients in bold are statistically significant at the $p<.05$ level. Correlation coefficients in bold and gray-shaded are statistically significant at the $p<.001$ level. 
Table 6

Situation Characteristics Predicting Teacher- and Supervisor-Rated Personality States (Question 2)

\begin{tabular}{|c|c|c|c|c|c|c|c|c|c|c|c|c|c|c|c|c|c|c|c|c|}
\hline \multirow{3}{*}{ Predictive Models } & \multicolumn{8}{|c|}{ Teachers } & \multirow{2}{*}{\multicolumn{4}{|c|}{ Consensus-focused situation contact }} & \multicolumn{8}{|c|}{ Supervisors } \\
\hline & \multicolumn{4}{|c|}{ Teacher-rated situation experience } & \multicolumn{4}{|c|}{ Teacher-focused situation construal } & & & & & \multicolumn{4}{|c|}{ Supervisor-rated situation experience } & \multicolumn{4}{|c|}{ Supervisor-focused situation construal } \\
\hline & $b$ & $95 \% \mathrm{CI}$ & $t$ & $R_{m}$ & $b$ & $95 \% \mathrm{CI}$ & $t$ & $R_{m}$ & $b$ & $95 \% \mathrm{CI}$ & $t$ & $R_{m}$ & $b$ & $95 \% \mathrm{CI}$ & $t$ & $R_{m}$ & $b$ & $95 \% \mathrm{CI}$ & $t$ & $R_{m}$ \\
\hline \multicolumn{21}{|l|}{$\begin{array}{l}\text { Teacher-rated } \\
\text { personality states }\end{array}$} \\
\hline $\begin{array}{r}\text { personality states } \\
\text { Extraversion }\end{array}$ & & & & .34 & & & & .37 & & & & .36 & & & & .21 & & & & .13 \\
\hline Adversity & 0.01 & {$[-0.01 ; 0.04]$} & 1.20 & & 0.00 & {$[-0.03 ; 0.04]$} & 0.18 & & 0.01 & {$[-0.04 ; 0.07]$} & 0.48 & & 0.02 & {$[-0.03 ; 0.06]$} & 0.77 & & 0.04 & {$[-0.01 ; 0.08]$} & 1.57 & \\
\hline Positivity & 0.19 & {$[0.16 ; 0.22]$} & 11.44 & & 0.27 & {$[0.21 ; 0.33]$} & 9.13 & & 0.29 & {$[0.18 ; 0.40]$} & 5.03 & & 0.01 & {$[-0.05 ; 0.07]$} & 0.37 & & -0.08 & {$[-0.15 ;-0.01]$} & -2.38 & \\
\hline Negativity & -0.12 & {$[-0.15 ;-0.09]$} & -7.27 & & -0.10 & {$[-0.15 ;-0.04]$} & -3.71 & & -0.31 & {$[-0.42 ;-0.22]$} & -6.02 & & -0.17 & {$[-0.23 ;-0.11]$} & -5.18 & & -0.11 & {$[-0.18 ;-0.04]$} & -3.12 & \\
\hline Humor & 0.10 & {$[0.07 ; 0.12]$} & 7.84 & & 0.10 & {$[0.05 ; 0.14]$} & 4.40 & & 0.22 & {$[0.15 ; 0.29]$} & 5.98 & & 0.09 & {$[0.05 ; 0.14]$} & 3.75 & & 0.07 & {$[0.02 ; 0.12]$} & 2.75 & \\
\hline Openness & & & & .31 & & & & .29 & & & & .30 & & & & .14 & & & & .07 \\
\hline Intellect & 0.13 & {$[0.09 ; 0.16]$} & 7.51 & & 0.12 & {$[0.05 ; 0.19]$} & 3.81 & & 0.30 & {$[0.15 ; 0.46]$} & 3.67 & & 0.06 & {$[-0.02 ; 0.13]$} & 1.45 & & 0.03 & {$[-0.04 ; 0.12]$} & 0.82 & \\
\hline Typicality & -0.01 & {$[-0.04 ; 0.02]$} & -0.73 & & 0.02 & {$[-0.03 ; 0.08]$} & 0.56 & & 0.01 & {$[-0.09 ; 0.13]$} & 0.28 & & 0.01 & {$[-0.06 ; 0.07]$} & 0.16 & & -0.01 & {$[-0.08 ; 0.05]$} & -0.38 & \\
\hline Conscientiousness & & & & .25 & & & & .23 & & & & .22 & & & & .09 & & & & .01 \\
\hline Duty & 0.24 & {$[0.21 ; 0.27]$} & 16.44 & & 0.24 & {$[0.18 ; 0.29]$} & 9.03 & & 0.44 & {$[0.33 ; 0.54]$} & 8.71 & & 0.10 & {$[0.04 ; 0.16]$} & 3.44 & & 0.01 & {$[-0.06 ; 0.06]$} & 0.22 & \\
\hline Neuroticism & & & & .38 & & & & .33 & & & & .37 & & & & .21 & & & & .09 \\
\hline Adversity & -0.02 & {$[-0.04 ; 0.01]$} & -1.17 & & 0.01 & {$[-0.04 ; 0.06]$} & 0.41 & & -0.00 & {$[-0.08 ; 0.07]$} & -0.05 & & 0.00 & {$[-0.06 ; 0.06]$} & 0.03 & & -0.02 & {$[-0.08 ; 0.05]$} & -0.77 & \\
\hline Positivity & -0.27 & {$[-0.31 ;-0.22]$} & -13.14 & & -0.31 & {$[-0.38 ;-0.22]$} & -7.72 & & -0.53 & {$[-0.68 ;-0.37]$} & -6.98 & & -0.14 & {$[-0.23 ;-0.05]$} & -3.33 & & -0.05 & {$[-0.13 ; 0.03]$} & -1.11 & \\
\hline Negativity & 0.30 & {$[0.26 ; 0.33]$} & 15.01 & & 0.22 & {$[0.14 ; 0.29]$} & 5.94 & & 0.52 & {$[0.38 ; 0.68]$} & 7.43 & & 0.22 & {$[0.13 ; 0.30]$} & 4.84 & & 0.11 & {$[0.03 ; 0.21]$} & 2.42 & \\
\hline Agreeableness & & & & .29 & & & & .28 & & & & .28 & & & & .15 & & & & .05 \\
\hline Adversity & -0.03 & {$[-0.05 ;-0.02]$} & -4.43 & & -0.04 & {$[-0.06 ;-0.01]$} & -2.53 & & -0.04 & {$[-0.09 ;-0.00]$} & -2.11 & & -0.01 & {$[-0.04 ; 0.03]$} & -0.39 & & 0.02 & {$[-0.02 ; 0.05]$} & 0.91 & \\
\hline Positivity & 0.10 & {$[0.08 ; 0.12]$} & 8.94 & & 0.13 & {$[0.09 ; 0.17]$} & 6.17 & & 0.20 & {$[0.12 ; 0.28]$} & 4.83 & & 0.05 & {$[0.00 ; 0.09]$} & 2.24 & & 0.00 & {$[-0.04 ; 0.05]$} & 0.16 & \\
\hline Negativity & -0.11 & {$[-0.13 ;-0.08]$} & 9.34 & & -0.09 & {$[-0.14 ;-0.06]$} & -4.65 & & -0.22 & {$[-0.29 ;-0.13]$} & -5.70 & & -0.09 & {$[-0.14 ;-0.04]$} & -3.84 & & -0.04 & {$[-0.09 ; 0.00]$} & -1.75 & \\
\hline \multicolumn{21}{|l|}{$\begin{array}{l}\text { Supervisor-rated } \\
\text { personality states }\end{array}$} \\
\hline Extraversion & & & & .12 & & & & .07 & & & & .23 & & & & .28 & & & & .24 \\
\hline Positivity & 0.04 & {$[-0.03 ; 0.10]$} & 1.22 & & -0.00 & {$[-0.07 ; 0.07]$} & -0.01 & & 0.19 & {$[0.08 ; 0.31]$} & 3.14 & & 0.13 & {$[0.08 ; 0.18]$} & 5.24 & & 0.14 & {$[0.08 ; 0.20]$} & 4.43 & \\
\hline Negativity & -0.05 & {$[-0.11 ; 0.02]$} & -1.63 & & 0.00 & {$[-0.05 ; 0.07]$} & 0.14 & & -0.19 & {$[-0.28 ;-0.07]$} & -3.32 & & -0.19 & {$[-0.25 ;-0.14]$} & -7.37 & & -0.15 & {$[-0.22 ;-0.09]$} & -4.56 & \\
\hline Humor & 0.07 & {$[0.02 ; 0.12]$} & 2.88 & & 0.06 & {$[0.01 ; 0.11]$} & 2.52 & & 0.20 & {$[0.12 ; 0.27]$} & 4.97 & & 0.13 & {$[0.09 ; 0.17]$} & 6.51 & & 0.12 & {$[0.07 ; 0.17]$} & 4.84 & \\
\hline Openness & & & & .13 & & & & .11 & & & & .22 & & & & .29 & & & & .23 \\
\hline Intellect & -0.03 & {$[-0.09 ; 0.03]$} & -0.85 & & -0.08 & {$[-0.15 ;-0.01]$} & -2.40 & & 0.26 & {$[0.11 ; 0.42]$} & 3.39 & & 0.27 & {$[0.21 ; 0.33]$} & 9.48 & & 0.25 & {$[0.18 ; 0.31]$} & 7.04 & \\
\hline Typicality & 0.01 & {$[-0.04 ; 0.06]$} & 0.42 & & 0.01 & {$[-0.04 ; 0.06]$} & 0.52 & & 0.03 & {$[-0.08 ; 0.12]$} & 0.60 & & 0.05 & {$[0.01 ; 0.10]$} & 2.25 & & 0.03 & {$[-0.04 ; 0.08]$} & 0.85 & \\
\hline Humor & 0.14 & {$[0.08 ; 0.19]$} & 5.17 & & 0.10 & {$[0.05 ; 0.16]$} & 3.80 & & 0.34 & {$[0.26 ; 0.44]$} & 7.72 & & 0.21 & {$[0.16 ; 0.25]$} & 9.42 & & 0.16 & {$[0.10 ; 0.22]$} & 5.60 & \\
\hline Conscientiousness & & & & .06 & & & & .00 & & & & .18 & & & & .23 & & & & .22 \\
\hline Duty & 0.06 & {$[0.01 ; 0.11]$} & 2.51 & & -0.00 & {$[-0.05 ; 0.05]$} & -0.02 & & 0.36 & {$[0.26 ; 0.45]$} & 7.47 & & 0.26 & {$[0.22 ; 0.30]$} & 11.49 & & 0.26 & {$[0.20 ; 0.31]$} & 9.14 & \\
\hline Neuroticism & & & & .15 & & & & .06 & & & & .26 & & & & .31 & & & & .26 \\
\hline Adversity & 0.00 & {$[-0.04 ; 0.05]$} & 0.16 & & 0.03 & {$[-0.03 ; 0.08]$} & 1.02 & & -0.03 & {$[-0.09 ; 0.05]$} & -0.79 & & 0.01 & {$[-0.03 ; 0.05]$} & 0.33 & & 0.00 & {$[-0.06 ; 0.06]$} & 0.09 & \\
\hline Positivity & -0.10 & {$[-0.18 ;-0.02]$} & -2.53 & & -0.02 & {$[-0.10 ; 0.05]$} & -0.60 & & -0.40 & {$[-0.55 ;-0.25]$} & -5.40 & & -0.27 & {$[-0.33 ;-0.22]$} & -9.00 & & -0.26 & {$[-0.34 ;-0.20]$} & -6.86 & \\
\hline Negativity & 0.11 & {$[0.04 ; 0.18]$} & 3.16 & & 0.05 & {$[-0.03 ; 0.13]$} & 1.25 & & 0.33 & {$[0.18 ; 0.47]$} & 4.85 & & 0.24 & {$[0.18 ; 0.30]$} & 7.24 & & 0.19 & {$[0.12 ; 0.27]$} & 4.85 & \\
\hline Agreeableness & & & & .10 & & & & .04 & & & & .17 & & & & .21 & & & & .16 \\
\hline Adversity & 0.02 & {$[-0.00 ; 0.05]$} & 1.74 & & 0.01 & {$[-0.01 ; 0.04]$} & 0.92 & & 0.05 & {$[0.01 ; 0.08]$} & 2.61 & & 0.01 & {$[-0.01 ; 0.04]$} & 1.40 & & 0.01 & {$[-0.02 ; 0.04]$} & 0.64 & \\
\hline Positivity & 0.04 & {$[0.00 ; 0.08]$} & 2.13 & & 0.02 & {$[-0.02 ; 0.06]$} & 1.02 & & 0.11 & {$[0.03 ; 0.19]$} & 2.95 & & 0.06 & {$[0.04 ; 0.09]$} & 4.22 & & 0.06 & {$[0.03 ; 0.10]$} & 3.26 & \\
\hline Negativity & -0.04 & {$[-0.08 ;-0.00]$} & -2.26 & & -0.01 & {$[-0.05 ; 0.02]$} & -0.69 & & -0.15 & {$[-0.22 ;-0.09]$} & -4.32 & & -0.11 & {$[-0.14 ;-0.08]$} & -7.06 & & -0.09 & {$[-0.14 ;-0.05]$} & -4.52 & \\
\hline
\end{tabular}

Note. $b=$ unstandardized multilevel regression coefficient; $95 \% \mathrm{CI}=95 \%$ confidence interval, $R_{m}=$ marginal multiple $R$ (Nakagawa \& Schielzeth, 2013).

Situation characteristics were within-person centered. Regression coefficients in bold are statistically significant at the $p<.05$ level. Regression coefficients in bold and gray-shaded are statistically significant at the $p<.001$ level. 
Table 7

Within- and Between-Person Correlations Between Personality Traits and Self- and Other-Rated Personality States (Question 3)

\begin{tabular}{|c|c|c|c|c|c|c|c|c|c|c|c|c|c|c|c|}
\hline \multirow{2}{*}{ Traits } & \multicolumn{5}{|c|}{ Teacher-rated personality traits } & \multicolumn{5}{|c|}{ Teacher-rated personality states } & \multicolumn{5}{|c|}{ Supervisor-rated personality states } \\
\hline & $\mathrm{O}$ & $\mathrm{C}$ & $\mathrm{E}$ & A & $\mathrm{N}$ & $\mathrm{O}$ & $\mathrm{C}$ & $\mathrm{E}$ & $\mathrm{A}$ & $\mathrm{N}$ & $\mathrm{O}$ & $\mathrm{C}$ & $\mathrm{E}$ & $\mathrm{A}$ & $\mathrm{N}$ \\
\hline \multicolumn{16}{|c|}{ Teacher-rated personality traits } \\
\hline Openness & - & - & - & - & - & - & - & - & - & - & - & - & - & - & - \\
\hline Conscientiousness & -.02 & - & - & - & - & - & - & - & - & - & - & - & - & - & - \\
\hline Extraversion & .10 & .03 & - & - & - & - & - & - & - & - & - & - & - & - & - \\
\hline Agreeableness & .08 & .31 & .07 & - & - & - & - & - & - & - & - & - & - & - & - \\
\hline Neuroticism & -.19 & -.04 & -.41 & -.15 & - & - & - & - & - & - & - & - & - & - & - \\
\hline \multicolumn{16}{|c|}{ Teacher-rated personality states } \\
\hline Openness & .20 & .25 & .36 & .17 & -.14 & - & .32 & .44 & .23 & -.37 & .24 & .14 & .17 & .05 & -.13 \\
\hline Conscientiousness & -.08 & .48 & .19 & .22 & -.07 & .66 & - & .33 & .36 & -.40 & .12 & .15 & .11 & .03 & -.14 \\
\hline Extraversion & .01 & .19 & .35 & .22 & -.18 & .74 & .63 & - & .40 & -.47 & .14 & .12 & .21 & .10 & -.18 \\
\hline Agreeableness & .02 & .20 & .13 & .35 & -.16 & .56 & .63 & .75 & - & -.28 & .08 & .07 & .10 & .13 & -.11 \\
\hline Neuroticism & .04 & -.16 & -.35 & -.08 & .35 & -.66 & -.61 & -.73 & -.57 & - & -.17 & -.21 & -.24 & -.08 & .26 \\
\hline \multicolumn{16}{|c|}{ Supervisor-rated personality states } \\
\hline Openness & -.06 & .15 & .15 & -.06 & -.04 & .28 & .29 & .26 & .16 & -.37 & - & .38 & .35 & .18 & -.32 \\
\hline Conscientiousness & -.14 & .22 & .05 & .00 & .01 & .29 & .37 & .26 & .20 & -.35 & .76 & - & .24 & .24 & -.36 \\
\hline Extraversion & -.16 & .04 & .24 & -.09 & -.12 & .27 & .18 & .28 & .13 & -.38 & .69 & .58 & - & .21 & -.42 \\
\hline Agreeableness & -.13 & .05 & -.01 & .03 & -.02 & .25 & .15 & .23 & .17 & -.35 & .54 & .68 & .66 & - & -.20 \\
\hline Neuroticism & .05 & -.13 & -.19 & .03 & .21 & -.34 & -.27 & -.30 & -.20 & .48 & -.68 & -.65 & -.75 & -.59 & - \\
\hline
\end{tabular}

Note. $N=173$ student teachers ( $n=2,244-2,261$ self-reports); $N=94$ supervisors ( $n=1,110-1,122$ other-reports). For approximately $n=790$ of these observations, ratings of both teacher and supervisor were available. $\mathrm{O}=$ Openness, $\mathrm{C}=$ Conscientiousness, $\mathrm{E}=\mathrm{Ex}$ traversion, $\mathrm{A}=\mathrm{Agreeableness,} \mathrm{N}=$ Neuroticism. Correlation coefficients above the diagonal are within-person correlations; correlation coefficients below the diagonal are between-person correlations. Correlation coefficients in bold are statistically significant at the $p<.05$ level. Correlation coefficients in bold and gray-shaded are statistically significant at the $p<.001$ level. 


\section{Table 8}

Situation Characteristics, Personality Traits, and their Interactions Predicting Self-and Other-Rated Personality States (Question 3)

\begin{tabular}{|c|c|c|c|c|c|c|c|c|c|c|c|c|c|c|c|c|c|c|c|c|}
\hline \multirow{3}{*}{ Predictive Models } & \multicolumn{8}{|c|}{ Teachers } & \multirow{2}{*}{\multicolumn{4}{|c|}{ Consensus-focused situation contact }} & \multicolumn{8}{|c|}{ Supervisors } \\
\hline & \multicolumn{4}{|c|}{ Teacher-rated situation experience } & \multicolumn{4}{|c|}{ Teacher-focused situation construal } & & & & & \multicolumn{4}{|c|}{ Supervisor-rated situation experience } & \multicolumn{4}{|c|}{ Supervisor-focused situation construal } \\
\hline & $b$ & $95 \% \mathrm{CI}$ & $t$ & $R_{m}$ & $b$ & $95 \% \mathrm{CI}$ & $t$ & $R_{m}$ & $b$ & $95 \% \mathrm{CI}$ & $t$ & $R_{m}$ & $\frac{a}{b}$ & $95 \% \mathrm{CI}$ & $t$ & $R_{m}$ & $b$ & $95 \% \mathrm{CI}$ & $t$ & $R_{m}$ \\
\hline $\begin{array}{l}\text { Teacher-rated personality states } \\
\text { Extrayersion }\end{array}$ & & & & & & & & & & & & & & & & & & & & \\
\hline $\begin{array}{l}\text { Extraversion } \\
\text { Trait Extraversion }\end{array}$ & & & & .41 & & & & .48 & & & & .47 & & & & .37 & & & & .33 \\
\hline & 0.25 & {$[0.15 ; 0.34]$} & 4.96 & & 0.34 & {$[0.21 ; 0.49]$} & 4.76 & & 0.34 & {$[0.19 ; 0.47]$} & 4.73 & & 0.34 & {$[0.22 ; 0.49]$} & 4.78 & & 0.34 & {$[0.19 ; 0.48]$} & 4.75 & \\
\hline $\begin{array}{l}\text { Adversity } \\
\text { Positivity }\end{array}$ & 0.02 & {$[-0.00 ; 0.04]$} & 1.60 & & 0.00 & {$[-0.03 ; 0.04]$} & 0.18 & & 0.01 & {$[-0.04 ; 0.07]$} & 0.48 & & 0.02 & {$[-0.03 ; 0.06]$} & 0.81 & & 0.04 & {$[-0.00 ; 0.08]$} & 1.57 & \\
\hline $\begin{array}{l}\text { Positivity } \\
\text { Negativity }\end{array}$ & 0.19 & {$[0.15 ; 0.22]$} & 11.39 & & 0.27 & {$[0.21 ; 0.32]$} & 9.13 & & 0.29 & {$[0.19 ; 0.40]$} & 5.03 & & 0.01 & {$[-0.05 ; 0.07]$} & 0.36 & & -0.08 & {$[-0.14 ;-0.02]$} & -2.39 & \\
\hline Negativity & -0.12 & {$[-0.15 ;-0.09]$} & -7.41 & & -0.10 & {$[-0.15 ;-0.04]$} & -3.71 & & -0.31 & {$[-0.42 ;-0.21]$} & -6.02 & & -0.17 & {$[-0.25 ;-0.10]$} & -5.22 & & -0.11 & {$[-0.18 ;-0.04]$} & -3.12 & \\
\hline Humor & 0.10 & {$[0.07 ; 0.12]$} & 7.92 & & 0.10 & {$[0.05 ; 0.14]$} & 4.39 & & 0.22 & {$[0.15 ; 0.29]$} & 5.97 & & 0.09 & {$[0.04 ; 0.14]$} & 3.71 & & 0.07 & {$[0.02 ; 0.12]$} & 2.75 & \\
\hline Trait Extraversion $x$ Adversity & -0.04 & {$[-0.08 ;-0.02]$} & -2.72 & & & & & & & & & & & & tes & & & & - & \\
\hline Openness & & & & .34 & & & & .30 & & & & .31 & & & & .15 & & & & .10 \\
\hline Trait Openness & 0.19 & {$[0.05 ; 0.33]$} & 2.70 & & 0.13 & {$[-0.09 ; 0.35]$} & 1.14 & & 0.13 & {$[-0.13 ; 0.36]$} & 1.16 & & 0.13 & {$[-0.10 ; 0.36]$} & 1.13 & & 0.12 & {$[-0.09 ; 0.35]$} & 1.11 & \\
\hline Intellect & 0.13 & {$[0.09 ; 0.16]$} & 7.32 & & 0.12 & {$[0.06 ; 0.19]$} & 3.81 & & 0.30 & {$[0.14 ; 0.46]$} & 3.71 & & 0.06 & {$[-0.02 ; 0.14]$} & 1.47 & & 0.03 & {$[-0.04 ; 0.11]$} & 0.83 & \\
\hline Typicality & -0.01 & {$[-0.04 ; 0.02]$} & -0.67 & & 0.02 & {$[-0.03 ; 0.07]$} & 0.56 & & 0.01 & {$[-0.09 ; 0.11]$} & 0.27 & & 0.00 & {$[-0.06 ; 0.07]$} & 0.14 & & -0.01 & {$[-0.08 ; 0.05]$} & -0.38 & \\
\hline Humor & 0.25 & {$[0.22 ; 0.28]$} & 16.98 & & 0.27 & {$[0.21 ; 0.32]$} & 9.49 & & 0.45 & {$[0.37 ; 0.53]$} & 9.67 & & 0.13 & {$[0.07 ; 0.19]$} & 4.11 & & 0.07 & {$[0.00 ; 0.14]$} & 2.02 & \\
\hline Trait Openness x Intellect & 0.10 & {$[0.03 ; 0.17]$} & 2.66 & & 0.21 & & - & & & {$[0.01,0.00]$} & & & 0.10 & {$[0.01,0.1]$} & - & & - & {$[0.00,0.17]$} & - & \\
\hline Trait Openness x Humor & - & - & - & & - & - & - & & -0.23 & {$[-0.42 ;-0.04]$} & -2.32 & & - & - & - & & - & - & - & \\
\hline Conscientiousness & & & & .42 & & & & .37 & & & & .37 & & & & .31 & & & & .30 \\
\hline Trait Conscientiousness & 0.37 & {$[0.27 ; 0.48]$} & 7.30 & & 0.33 & {$[0.16 ; 0.50]$} & 4.03 & & 0.33 & {$[0.16 ; 0.48]$} & 4.03 & & 0.33 & {$[0.17 ; 0.48]$} & 4.04 & & 0.33 & {$[0.15 ; 0.49]$} & 4.05 & \\
\hline Duty & 0.24 & {$[0.21 ; 0.27]$} & 16.44 & & 0.24 & {$[0.19 ; 0.29]$} & 9.03 & & 0.44 & {$[0.34 ; 0.53]$} & 8.70 & & 0.10 & {$[0.04 ; 0.16]$} & 3.41 & & 0.01 & {$[-0.05 ; 0.07]$} & 0.22 & \\
\hline Neuroticism & & & & .45 & & & & .41 & & & & .44 & & & & .32 & & & & .26 \\
\hline Trait Neuroticism & 0.30 & {$[0.17 ; 0.41]$} & 5.00 & & 0.30 & {$[0.12 ; 0.48]$} & 3.44 & & 0.30 & {$[0.13 ; 0.49]$} & 3.44 & & 0.31 & {$[0.13 ; 0.47]$} & 3.42 & & 0.30 & {$[0.11 ; 0.47]$} & 3.42 & \\
\hline Adversity & -0.02 & {$[-0.04 ; 0.01]$} & -1.17 & & 0.01 & {$[-0.04 ; 0.07]$} & 0.41 & & 0.00 & {$[-0.07 ; 0.08]$} & -0.05 & & 0.00 & {$[-0.06 ; 0.06]$} & 0.01 & & -0.02 & {$[-0.08 ; 0.04]$} & -0.77 & \\
\hline Positivity & -0.27 & {$[-0.31 ;-0.23]$} & -13.14 & & -0.31 & {$[-0.39 ;-0.22]$} & -7.72 & & -0.53 & {$[-0.69 ;-0.39]$} & -6.98 & & -0.14 & {$[-0.22 ;-0.06]$} & -3.36 & & -0.05 & {$[-0.14 ; 0.04]$} & -1.11 & \\
\hline Negativity & 0.30 & {$[0.26 ; 0.34]$} & 15.01 & & 0.22 & {$[0.14 ; 0.30]$} & 5.94 & & 0.52 & {$[0.40 ; 0.68]$} & 7.43 & & 0.22 & {$[0.13 ; 0.30]$} & 4.82 & & 0.11 & {$[0.02 ; 0.20]$} & 2.42 & \\
\hline Agreeableness & & & & .38 & & & & .39 & & & & .39 & & & & .31 & & & & .28 \\
\hline Trait Agreeableness & 0.27 & {$[0.17 ; 0.38]$} & 5.09 & & 0.32 & {$[0.14 ; 0.47]$} & 4.07 & & 0.32 & {$[0.15 ; 0.47]$} & 4.08 & & 0.31 & {$[0.31 ; 0.08]$} & 3.95 & & 0.31 & {$[0.14 ; 0.47]$} & 3.99 & \\
\hline Adversity & -0.03 & {$[-0.05 ;-0.02]$} & -4.43 & & -0.04 & {$[-0.06 ;-0.01]$} & -2.54 & & -0.04 & {$[-0.08 ;-0.00]$} & -2.11 & & -0.01 & {$[-0.01 ; 0.02]$} & -0.40 & & 0.02 & {$[-0.02 ; 0.05]$} & 0.91 & \\
\hline Positivity & 0.10 & {$[0.08 ; 0.13]$} & 8.94 & & 0.13 & {$[0.09 ; 0.17]$} & 6.18 & & 0.20 & {$[0.12 ; 0.28]$} & 4.84 & & 0.05 & {$[0.05 ; 0.02]$} & 2.24 & & 0.00 & {$[-0.05 ; 0.05]$} & 0.17 & \\
\hline Negativity & -0.11 & {$[-0.13 ;-0.08]$} & -9.34 & & -0.09 & {$[-0.13 ;-0.05]$} & -4.66 & & -0.22 & {$[-0.30 ;-0.15]$} & -5.71 & & -0.09 & {$[-0.09 ; 0.02]$} & -3.82 & & -0.04 & {$[-0.10 ; 0.00]$} & -1.75 & \\
\hline Supervisor-rated personality states & & & & & & & & & & & & & & & & & & & & \\
\hline Extraversion & & & & .22 & & & & .19 & & & & .29 & & & & .34 & & & & .30 \\
\hline Trait Extraversion & 0.22 & {$[0.03 ; 0.40]$} & 2.33 & & 0.22 & {$[0.03 ; 0.41]$} & 2.35 & & 0.22 & {$[0.03 ; 0.41]$} & 2.34 & & 0.24 & {$[0.03 ; 0.43]$} & 2.50 & & 0.22 & {$[0.02 ; 0.41]$} & 2.34 & \\
\hline Adversity & 0.01 & {$[-0.03 ; 0.05]$} & 0.26 & & -0.02 & {$[-0.06 ; 0.02]$} & -0.84 & & 0.04 & {$[-0.02 ; 0.10]$} & 1.33 & & 0.03 & {$[-0.00 ; 0.07]$} & 1.88 & & 0.03 & {$[-0.01 ; 0.08]$} & 1.39 & \\
\hline Positivity & 0.04 & {$[-0.02 ; 0.11]$} & 1.20 & & 0.00 & {$[-0.06 ; 0.07]$} & -0.01 & & 0.19 & {$[0.07 ; 0.31]$} & 3.14 & & 0.13 & {$[0.08 ; 0.18]$} & 5.10 & & 0.13 & {$[0.07 ; 0.20]$} & 4.31 & \\
\hline Negativity & -0.05 & {$[-0.11 ; 0.01]$} & -1.61 & & 0.00 & {$[-0.05 ; 0.07]$} & 0.14 & & -0.19 & {$[-0.30 ;-0.08]$} & -3.32 & & -0.19 & {$[-0.24 ;-0.14]$} & $\begin{array}{l}3.09 \\
-7.09\end{array}$ & & -0.15 & {$[-0.21 ;-0.08]$} & -4.49 & \\
\hline Humor & 0.07 & {$[0.02 ; 0.11]$} & 2.86 & & 0.06 & {$[0.01 ; 0.11]$} & 2.52 & & 0.20 & {$[0.12 ; 0.27]$} & 4.96 & & 0.13 & {$[0.09 ; 0.17]$} & 6.53 & & 0.12 & {$[0.08 ; 0.17]$} & 5.06 & \\
\hline Trait Extraversion x Adversity & 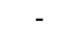 & . & & & & & & & & & & & -0.07 & {$[-0.13 ;-0.01]$} & -2.30 & & -0.08 & {$[-0.16 ;-0.00]$} & -2.05 & \\
\hline Openness & & & & .13 & & & & .13 & & & & .21 & & & & .29 & & & & .23 \\
\hline Trait Openness & 0.01 & {$[-0.23 ; 0.29]$} & 0.09 & & 0.00 & {$[-0.30 ; 0.27]$} & -0.02 & & 0.00 & {$[-0.28 ; 0.26]$} & -0.02 & & -0.01 & {$[-0.29 ; 0.23]$} & -0.07 & & 0.00 & {$[-0.26 ; 0.25]$} & -0.01 & \\
\hline Intellect & -0.03 & {$[-0.09 ; 0.03]$} & -0.85 & & -0.08 & {$[-0.13 ;-0.01]$} & -2.35 & & 0.26 & {$[0.11 ; 0.41]$} & 3.39 & & 0.27 & {$[0.21 ; 0.33]$} & 9.31 & & 0.25 & {$[0.18 ; 0.31]$} & 7.04 & \\
\hline Typicality & 0.01 & {$[-0.04 ; 0.06]$} & 0.42 & & 0.02 & {$[-0.03 ; 0.06]$} & 0.61 & & 0.03 & {$[-0.07 ; 0.12]$} & 0.60 & & 0.05 & {$[0.00 ; 0.10]$} & 2.14 & & 0.03 & {$[-0.03 ; 0.08]$} & 0.85 & \\
\hline Humor & 0.14 & {$[0.09 ; 0.19]$} & 5.17 & & 0.10 & {$[0.04 ; 0.16]$} & 3.63 & & 0.34 & {$[0.25 ; 0.43]$} & 7.72 & & 0.21 & {$[0.17 ; 0.26]$} & 9.40 & & 0.16 & {$[0.10 ; 0.22]$} & 5.60 & \\
\hline Trait Openness x Humor & & {$\left[\begin{array}{ll}0 \\
0\end{array}\right.$} & & & -0.14 & {$[-0.24 ;-0.01]$} & -2.30 & & & ( & 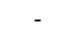 & & & & - & & $-1+2$ & - & - & \\
\hline Conscientiousness & & & & .23 & & & & .22 & & & & .29 & & & & .30 & & & & .31 \\
\hline Trait Conscientiousness & 0.24 & {$[0.07 ; 0.42]$} & 2.80 & & 0.24 & {$[0.05 ; 0.41]$} & 2.77 & & 0.24 & {$[0.08 ; 0.41]$} & 2.79 & & 0.21 & {$[0.02 ; 0.37]$} & 2.46 & & 0.24 & {$[0.07 ; 0.40]$} & 2.80 & \\
\hline Duty & 0.06 & {$[0.01 ; 0.11]$} & 2.55 & & 0.00 & {$[-0.05 ; 0.05]$} & -0.02 & & 0.36 & {$[0.26 ; 0.46]$} & 7.48 & & 0.26 & {$[0.21 ; 0.31]$} & 11.52 & & 0.26 & {$[0.20 ; 0.31]$} & 9.15 & \\
\hline Neuroticism & & & & .22 & & & & .16 & & & & .30 & & & & .35 & & & & .30 \\
\hline Trait Neuroticism & 0.18 & {$[0.00 ; 0.36]$} & 1.96 & & 0.18 & {$[-0.00 ; 0.36]$} & 1.90 & & 0.18 & {$[-0.02 ; 0.36]$} & 1.88 & & 0.20 & {$[0.02 ; 0.36]$} & 2.19 & & 0.18 & {$[-0.01 ; 0.37]$} & 1.88 & \\
\hline Adversity & 0.00 & {$[-0.05 ; 0.05]$} & 0.16 & & 0.03 & {$[-0.03 ; 0.07]$} & 1.02 & & -0.03 & {$[-0.11 ; 0.04]$} & -0.82 & & 0.01 & {$[-0.03 ; 0.06]$} & 0.34 & & 0.00 & {$[-0.05 ; 0.06]$} & 0.09 & \\
\hline Positivity & -0.10 & {$[-0.17 ;-0.02]$} & -2.53 & & -0.02 & {$[-0.10 ; 0.05]$} & -0.60 & & -0.41 & {$[-0.56 ;-0.26]$} & -5.52 & & -0.27 & {$[-0.33 ;-0.21]$} & -8.90 & & -0.26 & {$[-0.33 ;-0.19]$} & -6.86 & \\
\hline Negativity & 0.11 & {$[0.04 ; 0.18]$} & 3.16 & & 0.05 & {$[-0.04 ; 0.12]$} & 1.25 & & 0.34 & {$[0.20 ; 0.47]$} & 4.97 & & 0.24 & {$[0.17 ; 0.30]$} & 7.14 & & 0.19 & {$[0.11 ; 0.27]$} & 4.85 & \\
\hline Trait Neuroticism x Negativity & & & & & & & & & -0.19 & {$[-0.36 ;-0.03]$} & -2.14 & & & & & & & & - & \\
\hline Agreeableness & & & & .12 & & & & .07 & & & & .18 & & & & .21 & & & & .17 \\
\hline
\end{tabular}


Positivity

$\left.\left.\begin{array}{ll}0.06 \\ 0.02\end{array}\right]-0.09 ; 0.22\right]$

$\begin{array}{lll}0.04 & {[-0.00 ; 0.05]} & 1.73 \\ -0.04 & {[0.01 ; 0.08]} & 2.11\end{array}$

$\mathbf{- 0 . 0 4}[-0.08 ;-0.00]$

$\begin{array}{lll}0.06 & {[-0.11 ; 0.22]} & 0.80 \\ 0.01 & {[-0.02 ; 0.04]} & 0.92\end{array}$

$0.06 \quad[-0.09 ; 0.22]$

$[-0.02 ; 0.06] \quad 1.02$

$\begin{array}{lll}\mathbf{0 . 0 5} & {[0.01 ; 0.09]} & 0.80 \\ \mathbf{0 . 1 1} & 2.61\end{array}$

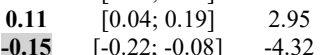

$0.04 \quad[-0.10 ; 0.20]$

$0.01 \quad[-0.01 ; 0.04]$

0.51
1.33

$0.06 \quad[-0.10 ; 0.21]$

$[-0.05 ; 0.03] \quad-0.69$

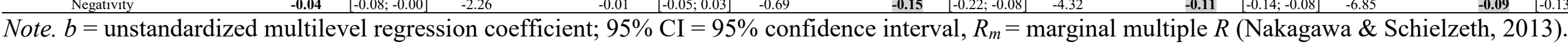

Note. $b=$ unstandardized multilevel regression coefficient; $95 \%$ CI $=95 \%$ confidence interval, $R_{m}=$ marginal multiple $R$ (Nakagawa \& Schielzeth, 2013).

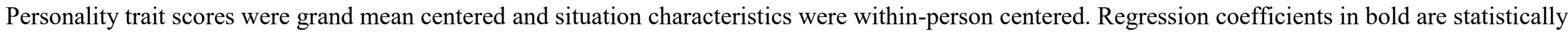
significant at the $p<.05$ level. Regression coefficients in bold and gray-shaded are statistically significant at the $p<.001$ level. 